\title{
Benzhydrylpyridinium lons: A New Class of Thermometer lons for the Characterization of Electrospray-Ionization Mass Spectrometers
}

Rene Rahrt, ${ }^{\dagger, \S}$ Thomas Auth, ${ }^{\dagger, \S}$ Maria Demireva, ${ }^{\ddagger \S}$ P. B. Armentrout, ${ }^{*, \neq}$ and Konrad Koszinowski, ${ }^{*} \dagger$

\author{
${ }^{\dagger}$ Institut für Organische und Biomolekulare Chemie, Universität Göttingen, Tammannstraße 2, 37077 Göttingen, \\ Germany \\ ${ }^{\ddagger}$ Department of Chemistry, University of Utah, 315 S. 1400 E., Salt Lake City, UT 84112, USA \\ §These authors contributed equally \\ E-mail: armentrout@chem.utah.edu,konrad.koszinowski@chemie.uni-goettingen.de
}

\section{Supporting Information}

\section{Table of Contents}

1) Complete Basis Set Limit Extrapolation $\quad S 2$

2) Synthesis and Analytical Data of Benzhydrylpyridinium Salts S3

3) ${ }^{1}$ H NMR Studies of Benzhydrylpyridinium Compounds $\quad$ S8

4) Details of Survival Yield Measurements and Analysis $\quad$ S9

5) Further Results from Quantum Chemical Calculations $\quad$ S10

6) Propagation of Uncertainty in Ion Temperature for GIBMS2 Thermochemistry S14

7) Further Results from Kinetic Shift Calculations $\quad$ S15

8) Further Results from Survival Yield Measurements and Analysis $\quad$ S20

9) References $\quad$ S30

10) Author Contributions $\quad$ S31 


\section{1) Complete Basis Set Limit Extrapolation}

On the basis of the results from DLPNO-CCSD $(T)$ single point energy calculations for cc-pVXZ and cc-pVYZ basis sets $(X, Y=T, Q$ or $D, T)$, the electronic energy $E_{\text {el }}(\infty)$ of a compound at the complete basis set (CBS) limit was determined according to the approach implemented in ORCA 4.0. ${ }^{1}$ Thus, the CBS $(X, Y)$ Hartree-Fock energy $E_{\mathrm{SCF}}(\infty)$ was calculated by the two-point extrapolation

$$
E_{\mathrm{SCF}}^{\infty}=\frac{E_{\mathrm{SCF}}^{\mathrm{cc}-\mathrm{pVYZ}} \cdot \exp (\alpha \sqrt{n})-E_{\mathrm{SCF}}^{\mathrm{cc}-\mathrm{pVXZ}} \cdot \exp (\alpha \sqrt{m})}{\exp (\alpha \sqrt{n})-\exp (\alpha \sqrt{m})}
$$

and the $\operatorname{CBS}(X, Y)$ correlation energy $E_{\text {corr }}(\infty)$ according to

$$
E_{\mathrm{corr}}^{\infty}=\frac{m^{\beta} E_{\mathrm{corr}}^{\mathrm{cc}-\mathrm{pVXZ}}-n^{\beta} E_{\mathrm{corr}}^{\mathrm{cc}-\mathrm{pVYZ}}}{m^{\beta}-n^{\beta}},
$$

where $m$ and $n$ correspond to the cardinal numbers of the cc-pVXZ and cc-pVYZ basis sets $(m, n=3,4$ for $X, Y=\mathrm{T}, \mathrm{Q}$ and $m, n=2,3$ for $X, Y=\mathrm{D}, \mathrm{T})$ and $\alpha$ and $\beta$ are optimized basis set specific parameters $(\alpha, \beta=5.46,3.05$ for $X, Y=\mathrm{T}, \mathrm{Q}$ and $\alpha, \beta=4.42,2.46$ for $X, Y=\mathrm{D}, \mathrm{T})$. $E_{\mathrm{el}}(\infty)$ is then the sum of $E_{\mathrm{SCF}}(\infty)$ and $E_{\mathrm{corr}}(\infty)$. 


\section{2) Synthesis and Analytical Data of Benzhydrylpyridinium Salts}

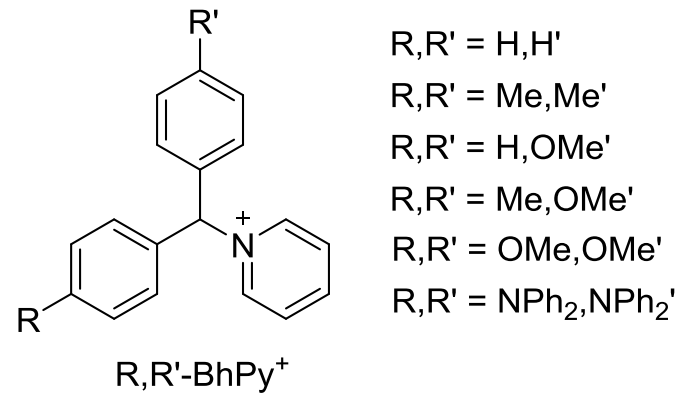

Scheme S1. Benzhydrylpyridinium ions used in this work.

The benzhydrylpyridinium salts were synthesized according to the following procedure: To a solution of the benzylhydryl chloride in acetonitrile pyridine was added. After stirring the reaction mixture at room temperature for $24 \mathrm{~h}$ and the removal of all volatiles under reduced pressure, the products were obtained as colorless powders. In the case of the $\mathrm{NPh}_{2}, \mathrm{NPh}_{2}{ }^{-}-\mathrm{BhPy}^{+}$system, the corresponding benzhydrylium tetrafluoroborate was used as reactant. The resulting product showed a light blue color, which indicated the presence of small amounts of the free benzhydrylium ion for this system.

\section{H,H'-Benzhydrylpyridinium Chloride}

Reactants: $\mathrm{H}, \mathrm{H}^{\prime}$-benzhydryl chloride $(0.71 \mathrm{~mL}, 0.81 \mathrm{~g}, 4.0 \mathrm{mmol}, 1.0$ equiv. $)$, pyridine $(0.42 \mathrm{~mL}, 0.41 \mathrm{~g}, 5.2 \mathrm{mmol}$, 1.3 equiv.); solvent: acetonitrile (10 mL); yield: $0.98 \mathrm{~g}, 3.2 \mathrm{mmol}, 80 \%$.

${ }^{1} \mathrm{H}$ NMR $\left(300 \mathrm{MHz}\right.$, methanol- $\left.d_{4}\right): \delta / p p m=8.98-8.94(\mathrm{~m}, 2 \mathrm{H}, \mathrm{Py}-\mathrm{H}), 8.72-8.64(\mathrm{~m}, 1 \mathrm{H}, \mathrm{Py}-\mathrm{H}), 8.20-8.12(\mathrm{~m}, 2 \mathrm{H}$, Py-H), 7.59 (s, 1H, Ar $\left.r_{2}-\mathrm{CH}\right), 7.54-7.47(\mathrm{~m}, 6 \mathrm{H}, \mathrm{Ar}-\mathrm{H}), 7.31-7.26(\mathrm{~m}, 4 \mathrm{H}, \mathrm{Ar}-\mathrm{H})$.

\section{Me,Me'-Benzhydrylpyridinium Chloride}

Reactants: Me,Me'-benzhydryl chloride $(0.16 \mathrm{~g}, 0.69 \mathrm{mmol}, 1.0$ equiv. $)$, pyridine $(0.10 \mathrm{~mL}, 0.10 \mathrm{~g}, 1.2 \mathrm{mmol}$, 1.7 equiv); solvent: acetonitrile $(6 \mathrm{~mL})$; yield: $0.10 \mathrm{~g}, 0.32 \mathrm{mmol}, 46 \%$.

${ }^{1} \mathrm{H}$ NMR $\left(300 \mathrm{MHz}\right.$, methanol- $\left.d_{4}\right): \delta / p p m=8.96-8.90(\mathrm{~m}, 2 \mathrm{H}, \mathrm{Py}-\mathrm{H}), 8.66(\mathrm{tt}, J=7.8,1.3 \mathrm{~Hz}, 1 \mathrm{H}, \mathrm{Py}-\mathrm{H}), 8.18-$ $8.10(\mathrm{~m}, 2 \mathrm{H}, \mathrm{Py}-\mathrm{H}), 7.50\left(\mathrm{~s}, 1 \mathrm{H}, \mathrm{Ar}_{2}-\mathrm{CH}\right), 7.35-7.28(\mathrm{~m}, 4 \mathrm{H}, \mathrm{Ar}-\mathrm{H}), 7.19-7.13(\mathrm{~m}, 4 \mathrm{H}, \mathrm{Ar}-\mathrm{H}), 2.38\left(\mathrm{~s}, 6 \mathrm{H}, \mathrm{CH}_{3}\right)$.

\section{OMe,H'-Benzhydrylpyridinium Chloride}

Reactants: OMe,H'-benzhydryl chloride $(0.12 \mathrm{~g}, 0.50 \mathrm{mmol}, 1.0$ equiv. $)$, pyridine $(0.07 \mathrm{~mL}, 0.07 \mathrm{~g}, 0.9 \mathrm{mmol}$, 1.3 equiv); solvent: acetonitrile $(6 \mathrm{~mL})$; yield: $0.072 \mathrm{~g}, 0.23 \mathrm{mmol}, 46 \%$.

${ }^{1} \mathrm{H}$ NMR $\left(300 \mathrm{MHz}\right.$, methanol- $\left.d_{4}\right): \delta / p p m=8.95-8.90(\mathrm{~m}, 2 \mathrm{H}, \mathrm{Py}-\mathrm{H}), 8.66(\mathrm{tt}, J=7.8,1.3 \mathrm{~Hz}, 1 \mathrm{H}, \mathrm{Py}-\mathrm{H}), 8.18-$ $8.10(\mathrm{~m}, 2 \mathrm{H}, \mathrm{Py}-\mathrm{H}), 7.51-7.46\left(\mathrm{~m}, 4 \mathrm{H}, \mathrm{Ar}-\mathrm{H}, \mathrm{Ar}_{2}-\mathrm{CH}\right), 7.27-7.20(\mathrm{~m}, 4 \mathrm{H}, \mathrm{Ar}-\mathrm{H}), 7.08-7.01(\mathrm{~m}, 2 \mathrm{H}, \mathrm{Ar}-\mathrm{H}), 3.84(\mathrm{~s}$, $\left.3 \mathrm{H}, \mathrm{OCH}_{3}\right)$.

\section{OMe,Me'-Benzhydrylpyridinium Chloride}

Reactants: OMe,Me'-benzhydryl chloride $(0.12 \mathrm{~g}, 0.49 \mathrm{mmol}, 1.0$ equiv.), pyridine $(0.07 \mathrm{~mL}, 0.07 \mathrm{~g}, 0.9 \mathrm{mmol}$, 1.8 equiv.); solvent: acetonitrile $(6 \mathrm{~mL})$; yield: $0.077 \mathrm{~g}, 0.23 \mathrm{mmol}, 47 \%$.

${ }^{1} \mathrm{H}$ NMR $\left(300 \mathrm{MHz}\right.$, methanol- $\left.d_{4}\right): \delta / \mathrm{ppm}=8.93-8.88(\mathrm{~m}, 2 \mathrm{H}, \mathrm{Py}-\mathrm{H}), 8.68-8.61(\mathrm{~m}, 1 \mathrm{H}, \mathrm{Py}-\mathrm{H}), 8.16-8.09(\mathrm{~m}, 2 \mathrm{H}$, $\mathrm{Py}-\mathrm{H}), 7.42\left(\mathrm{~s}, 1 \mathrm{H}, \mathrm{Ar}_{2}-\mathrm{CH}\right), 7.34-7.00(\mathrm{~m}, 8 \mathrm{H}, \mathrm{Ar}-\mathrm{H}), 3.83\left(\mathrm{~s}, 3 \mathrm{H}, \mathrm{OCH}_{3}\right), 2.38\left(\mathrm{~s}, 3 \mathrm{H}, \mathrm{CH}_{3}\right)$. The NMR analysis revealed that the reaction product contained residual reactants due to incomplete conversion.

\section{OMe,OMe'-Benzhydrylpyridinium Chloride}

Reactants: OMe,OMe'-benzhydryl chloride $(0.078 \mathrm{~g}, 0.30 \mathrm{mmol}, 1.0$ equiv. $)$, pyridine $(0.04 \mathrm{~mL}, 0.04 \mathrm{~g}, 0.5 \mathrm{mmol}$, 1.7 equiv.); solvent: acetonitrile $(6 \mathrm{~mL})$; yield: $0.043 \mathrm{~g}, 0.13 \mathrm{mmol}, 43 \%$.

${ }^{1} \mathrm{H}$ NMR $\left(300 \mathrm{MHz}\right.$, methanol- $\left.d_{4}\right): \delta / p p m=8.83-8.76(\mathrm{~m}, 2 \mathrm{H}, \mathrm{Py}-\mathrm{H}), 8.45(\mathrm{tt}, J=7.7,1.6 \mathrm{~Hz}, 1 \mathrm{H}, \mathrm{Py}-\mathrm{H}), 7.97-$ $7.90(\mathrm{~m}, 2 \mathrm{H}, \mathrm{Py}-\mathrm{H}), 7.24-7.17(\mathrm{~m}, 4 \mathrm{H}, \mathrm{Ar}-\mathrm{H}), 6.87-6.81(\mathrm{~m}, 4 \mathrm{H}, \mathrm{Ar}-\mathrm{H}), 5.17\left(\mathrm{~s}, 1 \mathrm{H}, \mathrm{Ar}_{2}-\mathrm{CH}\right), 3.74\left(\mathrm{~s}, 6 \mathrm{H}, \mathrm{OCH}_{3}\right)$. 


\section{$\mathrm{NPh}_{2}, \mathrm{NPh}_{2}{ }^{\prime}-$ Benzhydrylpyridinium Tetrafluoroborate $^{\prime}$}

Reactants: $\mathrm{NPh}_{2}, \mathrm{NPh}_{2}{ }^{\prime}$-benzhydrylium tetrafluoroborate $(0.18 \mathrm{~g}, 0.30 \mathrm{mmol}, 1.0$ equiv.), pyridine $(0.04 \mathrm{~mL}$, $0.04 \mathrm{~g}, 0.5 \mathrm{mmol}, 1.7$ equiv.); solvent: acetonitrile $(6 \mathrm{~mL})$; yield: $0.094 \mathrm{~g}$ crude product. The ${ }^{1} \mathrm{H}$ NMR spectrum of the reaction product in dichloromethane- $d_{2}$ showed two sets of pyridine signals indicating the partial dissociation of the benzhydrylpyridinium compound in solution, which prevented an unambiguous assignment of all signals.

As expected, the positive-ion mode ESI mass spectra of solutions of the synthesized benzhydrylpyridinium salts $\mathrm{R}, \mathrm{R}^{\prime}-\mathrm{BhPy}^{+} \mathrm{Cl}^{-}\left(\mathrm{R}, \mathrm{R}^{\prime}=\mathrm{H}, \mathrm{H}^{\prime} ; \mathrm{Me}, \mathrm{Me}^{\prime} ; \mathrm{H}, \mathrm{OMe}\right.$; Me,OMe'; OMe,OMe') in dichloromethane show the presence of the $\mathrm{R}, \mathrm{R}^{\prime}-\mathrm{BhPy}{ }^{+}$ions (Figures S1-S5). In addition, chloride-bound oligomers of the type (R, $\left.\mathrm{R}^{\prime}-\mathrm{BhPy}\right)_{n} \mathrm{Cl}_{n-1}{ }^{+}, n=2$ and 3 , exhibited high signal intensities. The simultaneously observed $\mathrm{R}, \mathrm{R}^{\prime}-\mathrm{Bh}^{+}$ions resulted from the fragmentation of the $\mathrm{R}, \mathrm{R}^{\prime}-\mathrm{BhPy}^{+}$ions during the ESI process and not from the presence of free $\mathrm{R}, \mathrm{R}^{\prime}-\mathrm{Bh}^{+}$ions in the sample solutions as their colorless appearance clearly demonstrated $\left(\mathrm{R}, \mathrm{R}^{\prime}-\mathrm{Bh}^{+}\right.$ions are intensely colored). ${ }^{2}$ The positiveion mode ESI mass spectrum of a solution of $\mathrm{NPh}_{2}, \mathrm{NPh}_{2}{ }^{\prime}-\mathrm{BhPy}^{+} \mathrm{BF}_{4}{ }^{-}$in dichloromethane only showed free $\mathrm{NPh}_{2}, \mathrm{NPh}_{2}{ }^{\prime}-\mathrm{Bh}^{+}$(Figure S6). This finding as well as the intense blue color of the sample solution point to the partial dissociation of $\mathrm{NPh}_{2}, \mathrm{NPh}_{2}{ }^{\prime}-\mathrm{BhPy}^{+}$in dichloromethane, in line with its known stability constant. ${ }^{3}$

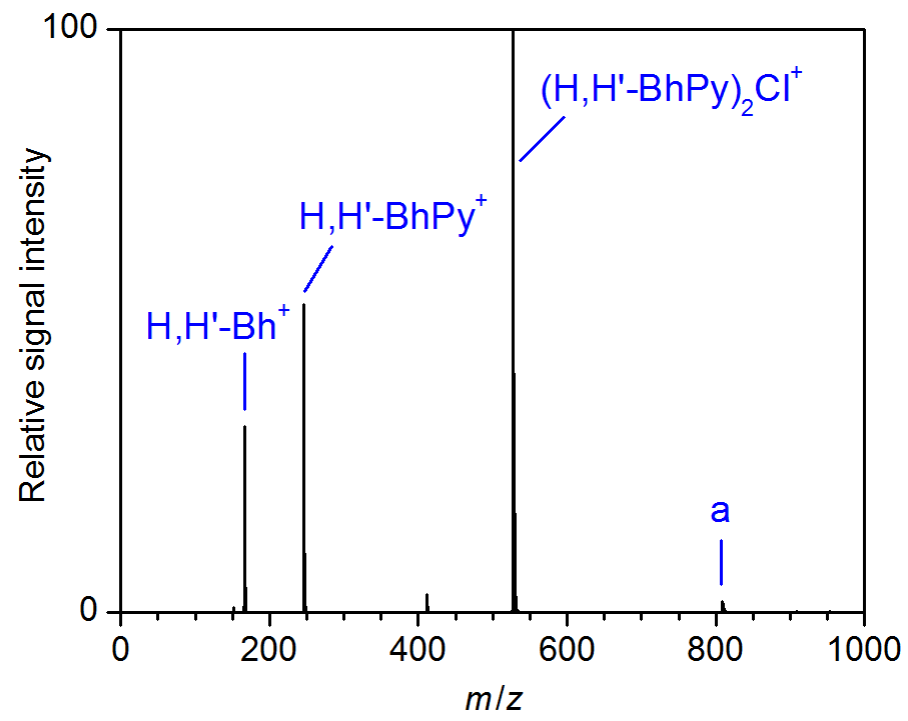

Figure S1. Positive-ion mode ESI mass spectrum of a solution of $\mathrm{H}, \mathrm{H}^{\prime}$-benzhydrylpyridinium chloride in dichloromethane (1 mM). a: $\left(\mathrm{H}, \mathrm{H}^{\prime}-\mathrm{BhPy}\right)_{3} \mathrm{Cl}_{2}^{+}$. 


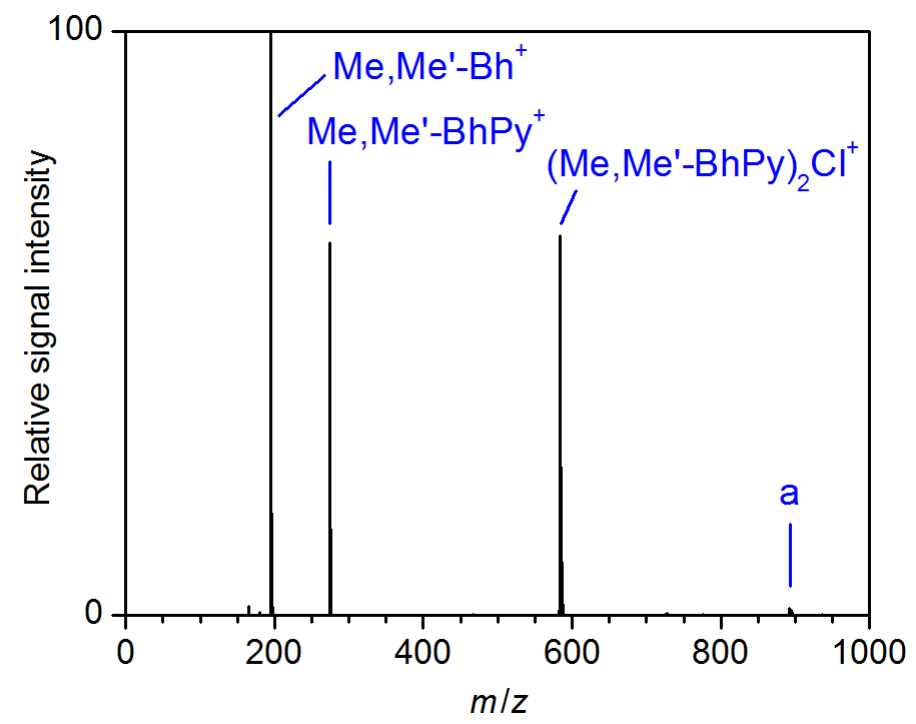

Figure S2. Positive-ion mode ESI mass spectrum of a solution of Me,Me'-benzhydrylpyridinium chloride in dichloromethane (1 mM). a: (Me, $\mathrm{Me}^{\prime}-\mathrm{BhPy}_{3} \mathrm{Cl}_{2}{ }^{+}$.

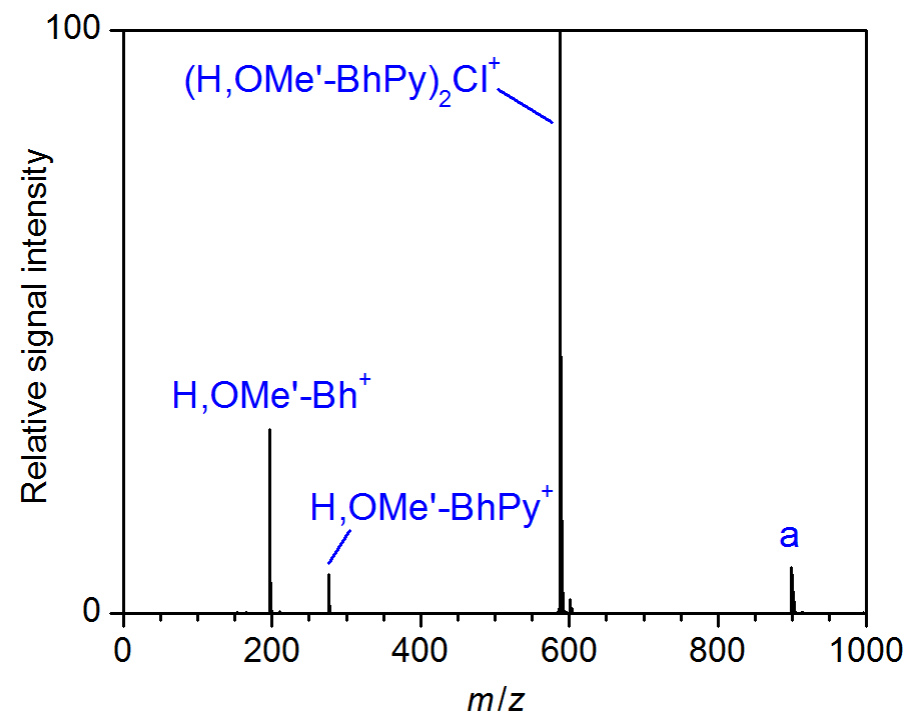

Figure S3. Positive-ion mode ESI mass spectrum of a solution of $\mathrm{H}, \mathrm{OMe}$-benzhydrylpyridinium chloride in dichloromethane (1 mM). a: $\left(\mathrm{H}, \mathrm{OMe}-\mathrm{BhPy}_{3} \mathrm{Cl}_{2}{ }^{+}\right.$. 


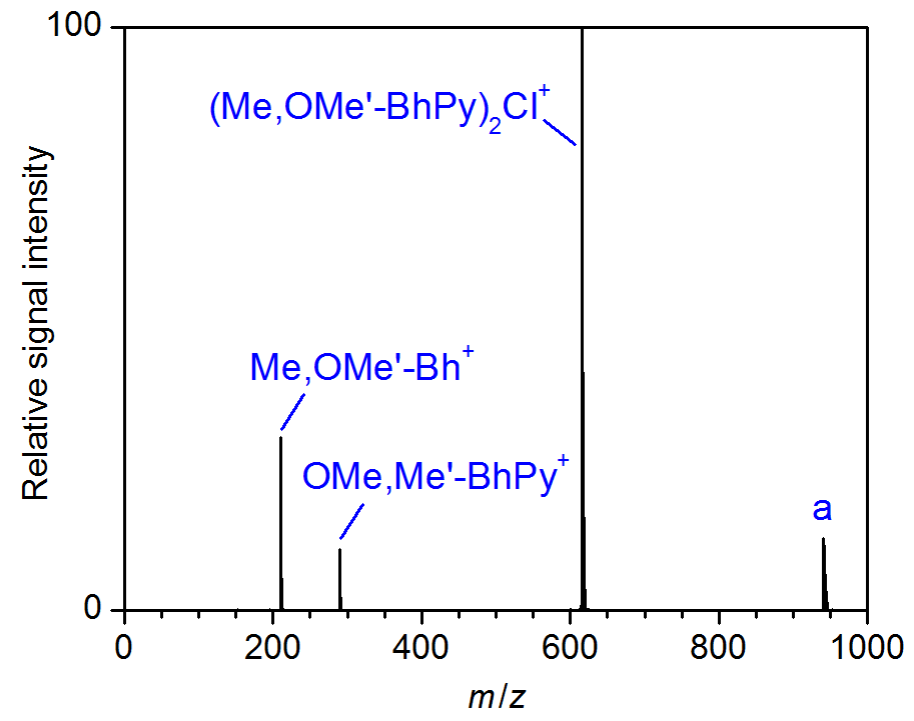

Figure S4. Positive-ion mode ESI mass spectrum of a solution of $\mathrm{Me}, \mathrm{OMe}$-benzhydrylpyridinium chloride in dichloromethane (1 mM). a: (Me,OMe'-BhPy) ${ }_{3} \mathrm{Cl}_{2}^{+}$.

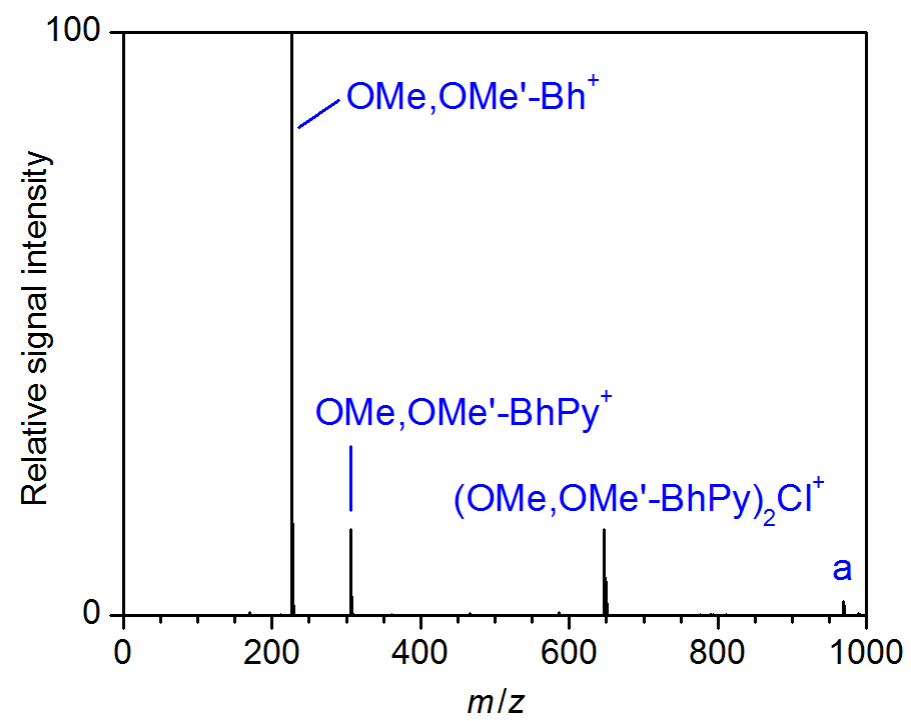

Figure S5. Positive-ion mode ESI mass spectrum of a solution of OMe,OMe'-benzhydrylpyridinium chloride in dichloromethane (1 mM). a: (OMe, $\mathrm{OMe}^{\prime}-\mathrm{BhPy}_{3} \mathrm{Cl}_{2}{ }^{+}$. 


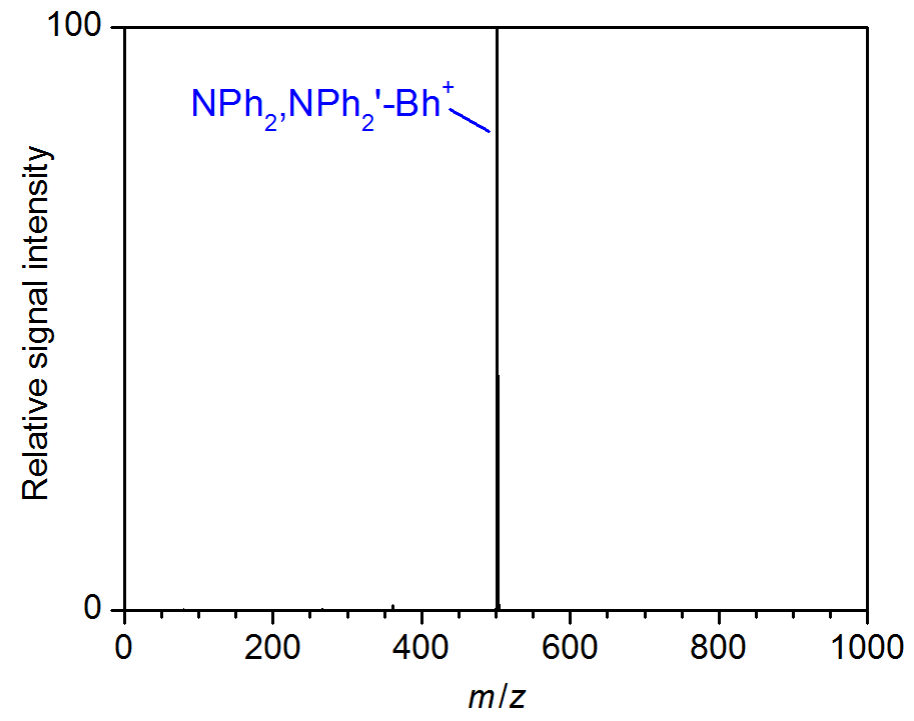

Figure S6. Positive-ion mode ESI mass spectrum of a solution of $\mathrm{NPh}_{2}, \mathrm{NPh}_{2}$-benzhydrylpyridinium tetrafluoroborate in dichloromethane (1 mM). No intact $\mathrm{NPh}_{2}, \mathrm{NPh}_{2}{ }^{\prime}$-benzhydrylpyridinium ions could be observed. 


\section{3) ${ }^{1} \mathrm{H}$ NMR Studies of Benzhydrylpyridinium Compounds}

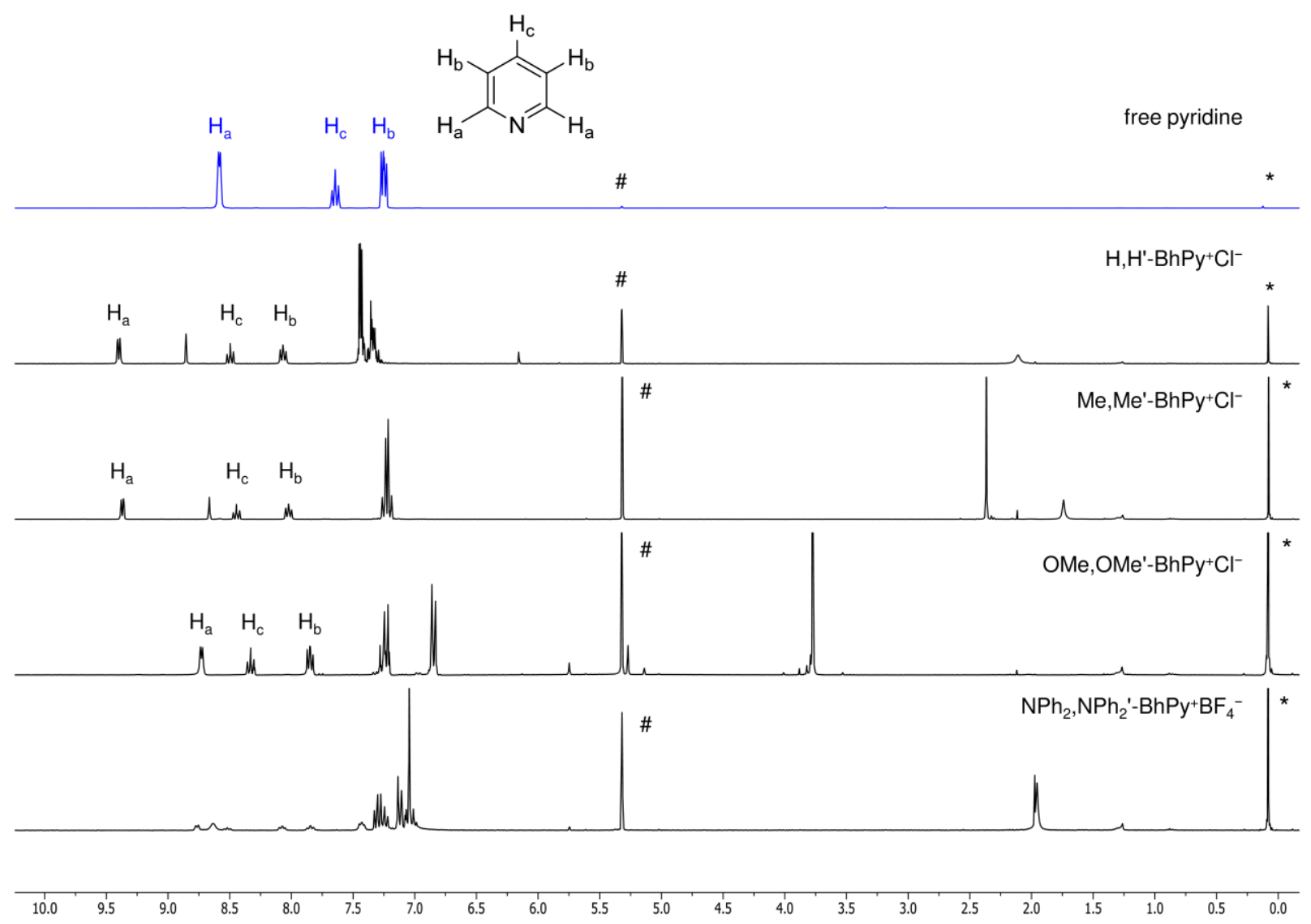

Figure S7. 'H NMR spectra $(300 \mathrm{MHz})$ of pyridine and benzhydrylpyridinium compounds in dichloromethane- $d_{2}$ $(0.03 \mathrm{M})$ at room temperature. Chemical shifts of the pyridinium protons are compared to the chemical shifts of free pyridine $\left(\mathrm{H}_{\mathrm{a}}, \mathrm{H}_{\mathrm{b}}, \mathrm{H}_{\mathrm{c}}\right)$. Signals corresponding to dichloromethane- $d_{2}(\#)$ and grease $\left({ }^{*}\right)$ are labeled. Only in the case of $\mathrm{NPh}_{2}, \mathrm{NPh}_{2}$--benzhydrylpyridinium tetrafluoroborate, two sets of pyridine signals indicative of the presence of the pyridinium ion and of free pyridine were observed. The absence of free pyridine for the $\mathrm{OMe}, \mathrm{OMe}^{\prime}-\mathrm{BhPy}^{+}$ system shows that this ion does not dissociate in dichloromethane to a significant extent. Accordingly, benzhydrylpyridinium ions more stable than $\mathrm{OMe}, \mathrm{OMe}^{\prime}-\mathrm{BhPy}^{+}$will not dissociate in dichloromethane either. 


\section{4) Details of Survival Yield Measurements and Analysis}

a) Instrument: microOTOF-Q II, Bruker Daltonics, equipped with ESI sprayer, Agilent Technologies

\section{Source}

$\begin{array}{ll}\text { End Plate Offset } & -500 \mathrm{~V} \\ \text { Capillary } & -4500 \mathrm{~V} \\ \text { Nebulizer } & 0.7 \mathrm{bar} \\ \text { Dry Gas } & 5.0 \mathrm{~L} \mathrm{~min}^{-1} \\ \text { Dry Temperature } & 50^{\circ} \mathrm{C}\end{array}$

\section{Tune}

Transfer

Funnel 1 RF

isCID Energy

$300.0 \mathrm{Vpp}$

$0.0 \mathrm{eV}$

Quadrupole

Ion Energy
Collision Cell

Collision Energy

Transfer Time

$4.0 \mathrm{eV}$

$0.0 \mathrm{eV}$

$77.0 \mu \mathrm{s}$

Flow Rate $\mathrm{N}_{2}$ Collision Cell $\quad 5 \%$

Syringe Pump Rate

$$
\begin{array}{ll}
\text { Funnel 2 RF } & 300.0 \mathrm{Vpp} \\
\text { Hexapole RF } & 200.0 \mathrm{Vpp}
\end{array}
$$

Low Mass

$50.0 \mathrm{~m} / \mathrm{z}$

Collision RF

Pre Pulse Storage $\quad 1.0 \mu \mathrm{s}$ against the corresponding $E_{\text {app }}$ or $E_{0}$ values:

$$
y=\frac{1}{1+\exp \left[-a\left(x-x_{0}\right)\right]},
$$

where the fitting parameters $x_{0}$ and a characterize the point of inflection and the maximal slope of the survival yield curve, respectively.

c) The given values of the mean energies and FWHM of the internal energy distributions of the thermometer ions were determined from the derivatives of the logistic regressions of the SY vs. $E_{\mathrm{app}}$ data for $T=10^{-4} \mathrm{~s}$. The error of each mean energy was calculated as the sum of the uncertainty arising from the uncertainty in $T$ and the corresponding statistical error from the regression. The given error of each FWHM, on the contrary, directly corresponds to the uncertainty resulting from the uncertainty in $T$. Likewise, the given approximate temperatures of the thermometer ions were also determined on the basis of the derivatives of the logistic regressions of the SY vs. $E_{\text {app }}$ data for $T=10^{-4} \mathrm{~S}$ and the corresponding errors directly derived from the uncertainty arising from the uncertainty in $T$. 


\section{5) Further Results from Quantum Chemical Calculations}
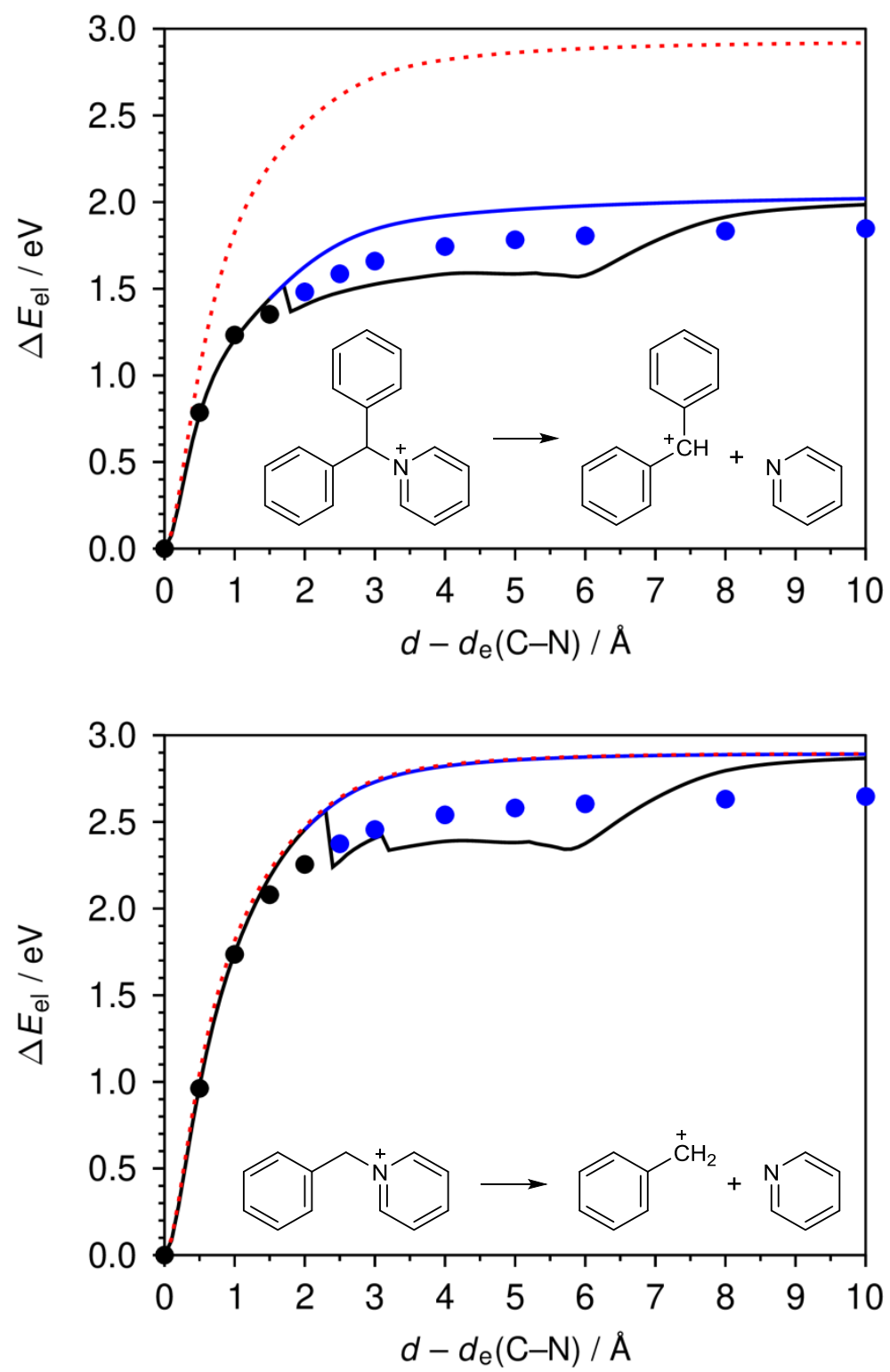

Figure S8. Relative electronic energies $\Delta E_{\text {el }}$ for benzhydrylpyridinium (top) and benzylpyridinium ions (bottom) as function of $d-d_{\mathrm{e}}(\mathrm{C}-\mathrm{N})$, the distance between the benzylic carbon atom and pyridine nitrogen relative to the equilibrium distance. The black solid lines correspond to energies obtained from relaxed potential energy scans using the PBE0-D3BJ/def2-SVP method. The non-monotonic behavior of the energy in the course of these scans originates from rearrangement processes after the cleavage of the $\mathrm{C}-\mathrm{N}$ bonds, which keep the free pyridine as close as possible to the ionic fragment within the given $d-d_{\mathrm{e}}(\mathrm{C}-\mathrm{N})$ constraint. To suppress these rearrangements, which do not correspond to the pure bond dissociation mechanism, partially unrelaxed potential energy scans were performed starting from geometries of the relaxed surface scans shortly before the first structural reorientation (blue solid lines). Within these scans, redundant internal coordinates defining the relative orientation between the fragments were held constant (only internal coordinates not involving hydrogen atom were constrained). In addition, analogous partially unrelaxed potential energy scans starting from the equilibrium geometries were carried out (red dotted lines). In the case of benzhydrylpyridinium, the latter is associated with a significantly higher dissociation energy because the constraints prevented the benzhydrylium fragment from adopting its equilibrium geometry during the scan. The DLPNO-CCSD(T)/cc-pVTZ single point energies calculated for selected structures obtained from the relaxed and partially unrelaxed surface scans (black and blue dots, respectively) validate that the pyridine loss reactions considered in this work do not feature a reverse barrier and thus, correspond to loose transition state dissociations. 

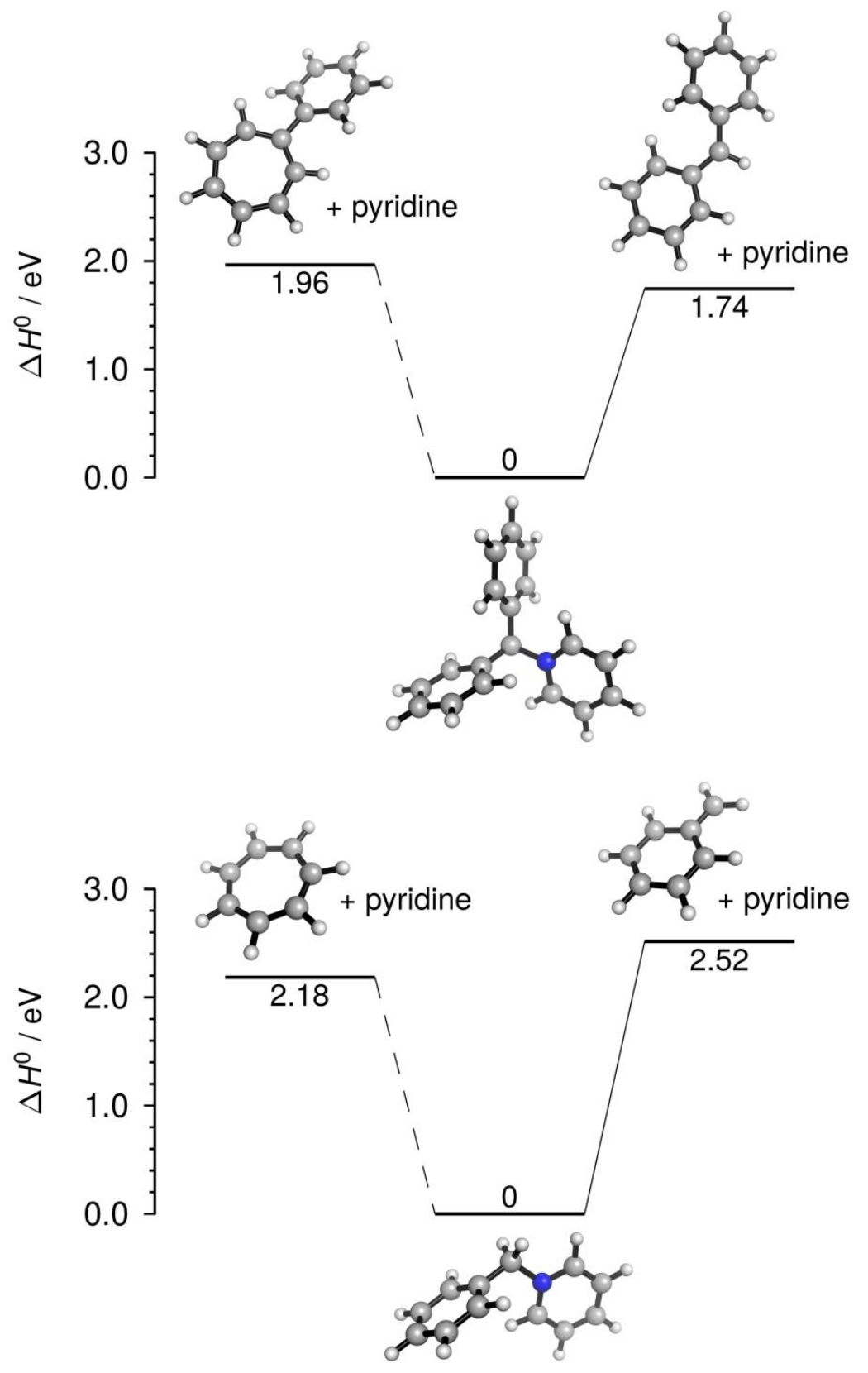

Figure S9. Relative enthalpies $\Delta H^{0} \quad(T=0 \mathrm{~K})$ for the potential products of the pyridine loss of benzhydrylpyridinium (top) and benzylpyridinium ions (bottom) obtained from DLPNO-CCSD(T)/CBS(T,Q)//PBE0D3BJ/def2-TZVP calculations. Products to the right correspond to the simple bond dissociation affording benzhydrylium and benzylium ions. Products to the left correspond to the loss of pyridine accompanied by the formation of a tropylium ring, which could either take place before or after $\mathrm{C}-\mathrm{N}$ bond cleavage. While experimental evidence has been provided that the thermochemically favored formation of a seven-membered ring in the case of benzylpyridinium ions occurs after the dissociation, ${ }^{4,5}$ our calculations indicate that any reaction pathway leading to a tropylium moiety is energetically unfavorable with respect to the pyridine loss of benzhydrylpyridinium ions. 

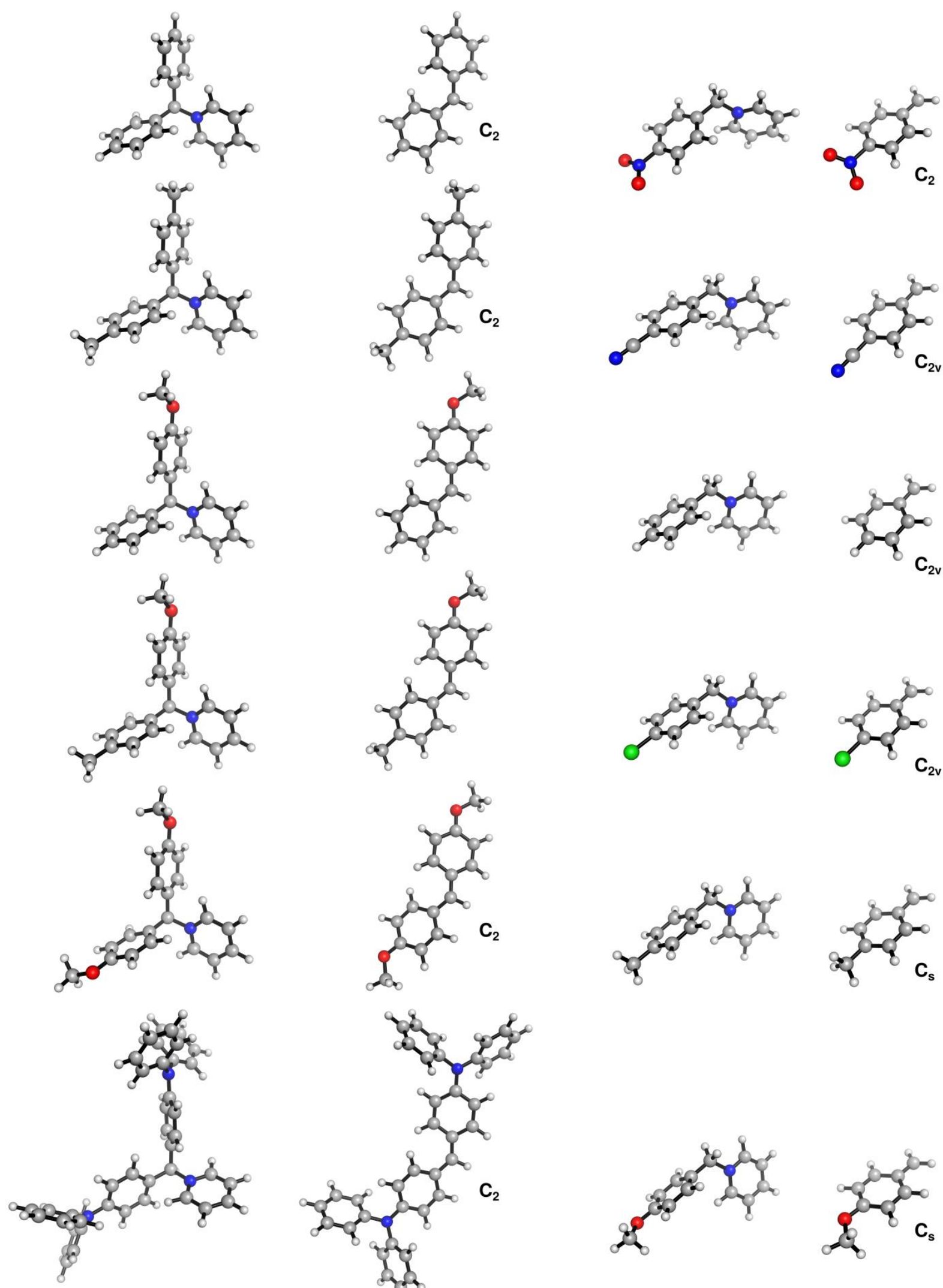

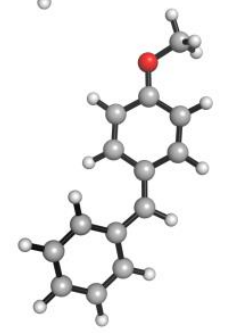

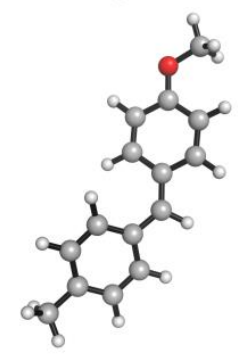
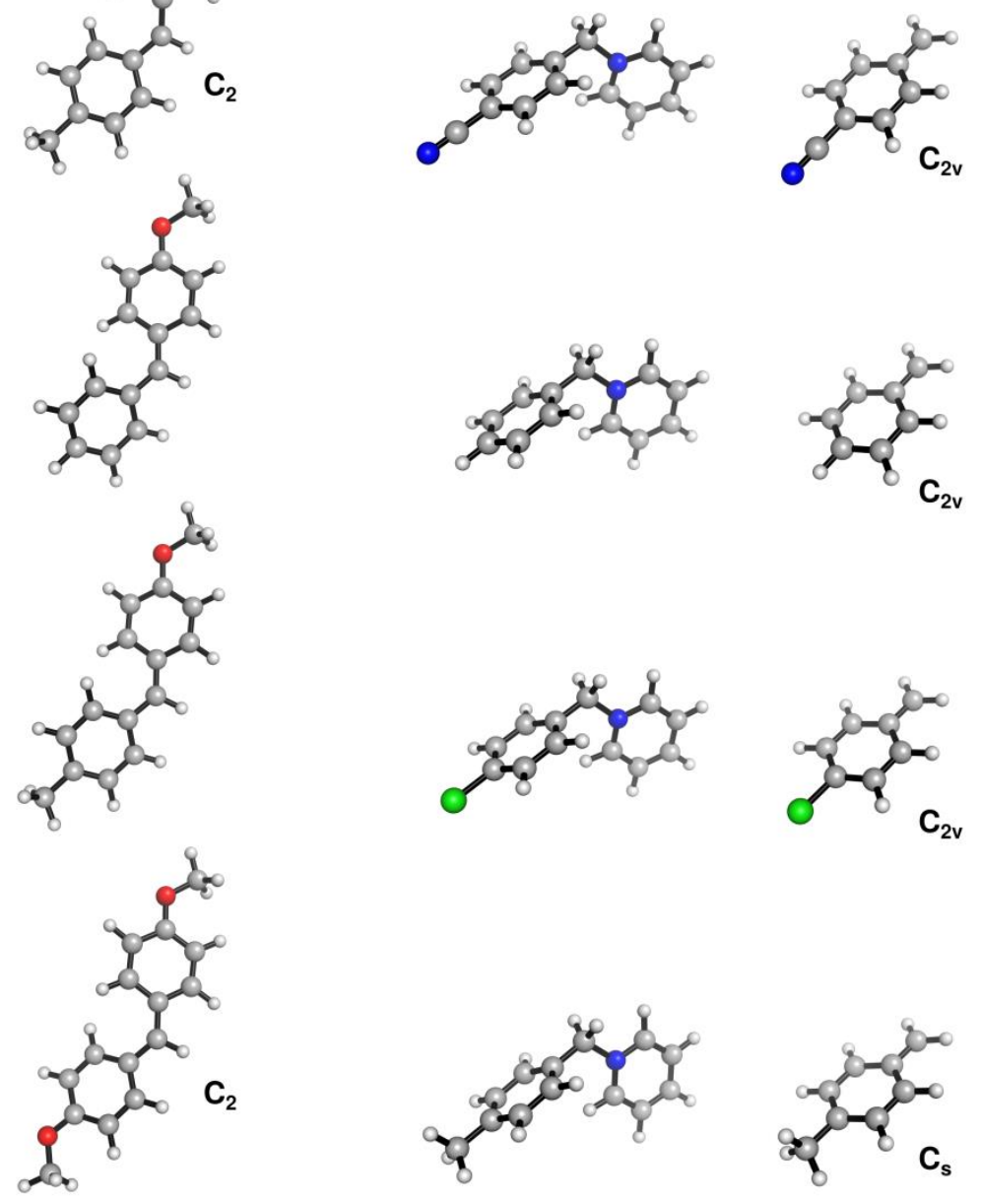

Figure S10. Molecular structures of benzhydrylpyridinium (first column; R,R' = H,H'; Me,Me'; H,OMe'; Me,OMe'; $\mathrm{OMe}, \mathrm{OMe}^{\prime} ; \mathrm{NPh}_{2}, \mathrm{NPh}_{2}{ }^{\prime}$ ) and benzylpyridinium ions (third column; $\mathrm{R}=\mathrm{NO}_{2}, \mathrm{CN}, \mathrm{H}, \mathrm{Cl}, \mathrm{Me}, \mathrm{OMe}$ ) and their pyridine loss products (second and fourth column) obtained from PBE0-D3BJ geometry optimizations. For each structure that is not $\mathrm{C}_{1}$-symmetric, the point group is given. The $\mathrm{C}_{2 v}$-symmetric free pyridine is not shown. 
Table S1. Electronic reaction energies $\Delta E_{\mathrm{el}}$ and threshold energies $E_{0}$ for the pyridine loss of benzhydryl- and benzylpyridinium ions obtained from DLPNO-CCSD(T)//PBE0-D3BJ calculations. Experimental $E_{0}$ values for benzylpyridinium ions from TCID experiments ${ }^{5}$ are listed for comparison. All values are given in eV.

\begin{tabular}{|c|c|c|c|c|c|}
\hline & $\Delta E_{\mathrm{el}}(\mathrm{cc}-\mathrm{p} \vee X Z)$ & $\Delta E_{\mathrm{el}}(\mathrm{cc}-\mathrm{p} \vee Y Z)$ & $\Delta E_{\mathrm{el}}(\mathrm{CBS})$ & $E_{0}(\mathrm{CBS})$ & $E_{0}(T C I D)$ \\
\hline $\mathrm{H}, \mathrm{H}^{\prime}-\mathrm{BhPy}^{+a}$ & 1.87 & 1.87 & 1.87 & 1.74 & \\
\hline $\mathrm{Me}, \mathrm{Me}^{\prime}-\mathrm{BhPy}^{+a}$ & 1.65 & 1.65 & 1.65 & 1.52 & \\
\hline $\mathrm{H}, \mathrm{OMe}^{\prime}-\mathrm{BhPy}^{+a}$ & 1.51 & 1.51 & 1.52 & 1.41 & \\
\hline $\mathrm{Me}, \mathrm{OMe}^{\prime}-\mathrm{BhPy}^{+a}$ & 1.44 & 1.44 & 1.44 & 1.33 & \\
\hline $\mathrm{OMe}, \mathrm{OMe}-\mathrm{BhPy}^{+a}$ & 1.27 & 1.28 & 1.29 & 1.18 & \\
\hline $\mathrm{NPh}_{2}, \mathrm{NPh}_{2}{ }^{\prime}-\mathrm{BhPy}^{+b}$ & 0.74 & 0.76 & 0.79 & 0.70 & \\
\hline $\mathrm{NO}_{2}-\mathrm{BnPy}^{+a}$ & 3.02 & 3.04 & 3.05 & 2.87 & $3.04 \pm 0.12$ \\
\hline $\mathrm{CN}-\mathrm{BnPy}^{+a}$ & 2.93 & 2.94 & 2.95 & 2.78 & \\
\hline $\mathrm{H}-\mathrm{BnPy}^{+a}$ & 2.67 & 2.67 & 2.68 & 2.52 & $2.58 \pm 0.15$ \\
\hline $\mathrm{Cl}-\mathrm{BnPy}^{+a}$ & 2.54 & 2.55 & 2.57 & 2.41 & \\
\hline $\mathrm{Me}-\mathrm{BnPy}^{+a}$ & 2.43 & 2.43 & 2.43 & 2.26 & $2.26 \pm 0.13$ \\
\hline $\mathrm{OMe}_{-\mathrm{BnPy}}{ }^{+a}$ & 1.98 & 1.99 & 2.00 & 1.85 & $1.93 \pm 0.08$ \\
\hline
\end{tabular}

${ }^{a} X, Y$ correspond to $\mathrm{T}, \mathrm{Q} .{ }^{b} X, Y$ correspond to $\mathrm{D}, \mathrm{T}$. 


\section{6) Propagation of Uncertainty in lon Temperature for GIBMS2 Thermochemistry}

As described in the manuscript, the temperature of the ions produced in the electrospray ionization (ESI) source that is coupled to GIBMS2 has not been characterized previously. This temperature can be calibrated by comparing the thermochemistry measured for the benzhydrylpyridinium cation $\mathrm{H}, \mathrm{H}^{\prime}-\mathrm{BhPy}^{+}$using GIBMS2 with that measured using GIBMS1, which has an ESI source known to produce thermalized ions at $300 \mathrm{~K}$. Modeling the kinetic energy dependent product ion cross sections for $\mathrm{H}, \mathrm{H}^{\prime}-\mathrm{BhPy}^{+}$obtained with GIBMS1 results in an $E_{0}$ value of $1.79 \pm 0.11 \mathrm{eV}$. To reproduce this $E_{0}$ value for the results obtained on GIBMS2, the $\mathrm{H}, \mathrm{H}^{\prime}-\mathrm{BhPy}^{+}$product ion cross section must be modeled using a temperature of $360 \mathrm{~K}$, as discussed in the manuscript. The uncertainty in the temperature for the GIBMS2 measurements can then be propagated from the $\pm 0.11 \mathrm{eV}$ uncertainty determined for the GIMBS1 results. For example, to reproduce the lower bound $E_{0}$ value of $1.68 \mathrm{eV}$ (i.e., $1.79-0.11 \mathrm{eV}$ ), the GIBMS2 data for $\mathrm{H}_{1} \mathrm{H}^{\prime}-\mathrm{BhPy}^{+}$need to be modeled using a temperature below $300 \mathrm{~K}$ (the $E_{0}$ value at $300 \mathrm{~K}$ is $1.70 \mathrm{eV}$ ), such that here the reasonable lower limit for the temperature is $300 \mathrm{~K}$. To reproduce the upper bound $E_{0}$ value of $1.90 \mathrm{eV}$ (i.e., $1.79+0.11 \mathrm{eV}$ ), a temperature of $405 \mathrm{~K}$ must be used to model the GIBMS2 results for $\mathrm{H}^{\prime} \mathrm{H}^{\prime}-\mathrm{BhPy}^{+}$. Thus, for the other two thermometer ions $\left(\mathrm{R}, \mathrm{R}^{\prime}-\mathrm{BhPy}^{+}\right.$with $\mathrm{R}, \mathrm{R}^{\prime}=\mathrm{Me}, \mathrm{Me}^{\prime}$ and $\mathrm{H}, \mathrm{OMe}$ ') studied exclusively with GIBMS2, the uncertainties in the $E_{0}$ values include the propagated uncertainty of the ion temperature by determining the range of $E_{0}$ values that can reproduce the data between 300 and $405 \mathrm{~K}$. 


\section{7) Further Results from Kinetic Shift Calculations}
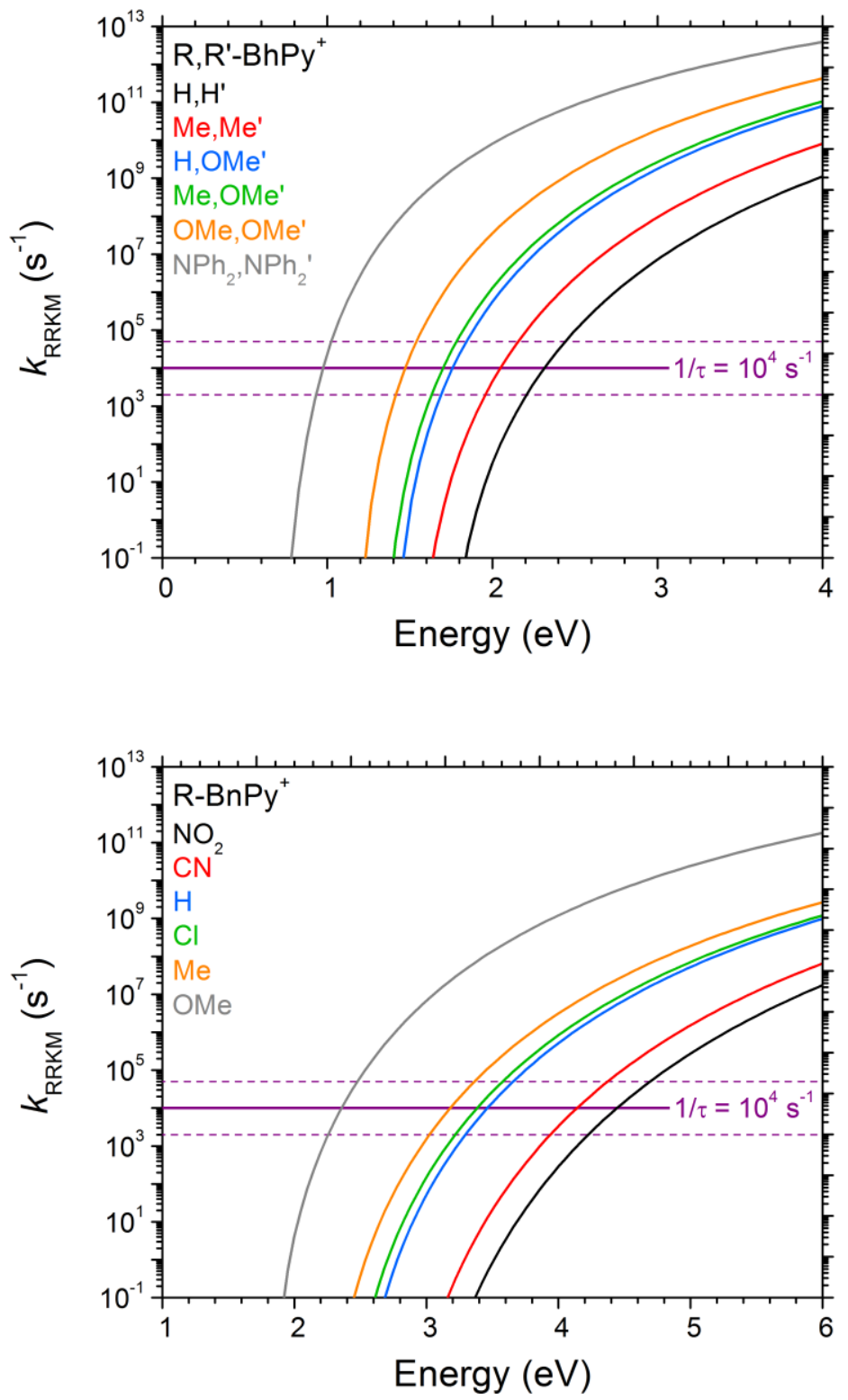

Figure S11. Microcanonical rate constants for the pyridine loss of benzhydrylpyridinium (top) and benzylpyridinium ions (bottom) obtained from PSL/RRKM calculations with $E_{0}$ values, vibrational frequencies and geometries from DLPNO-CCSD(T)//PBE0-D3BJ calculations. The intersections between the purple lines and the $k(E)$ curves correspond to the appearance energies of the dissociation reactions under the assumption of an experimental time scale of $T=10^{-4} \mathrm{~S}$ (solid purple line), $T=2 \cdot 10^{-5} \mathrm{~S}$ (upper dashed purple line) and $T=5 \cdot 10^{-4} \mathrm{~S}$ (lower dashed purple line). For the determined values, see Tables S2-S4. 


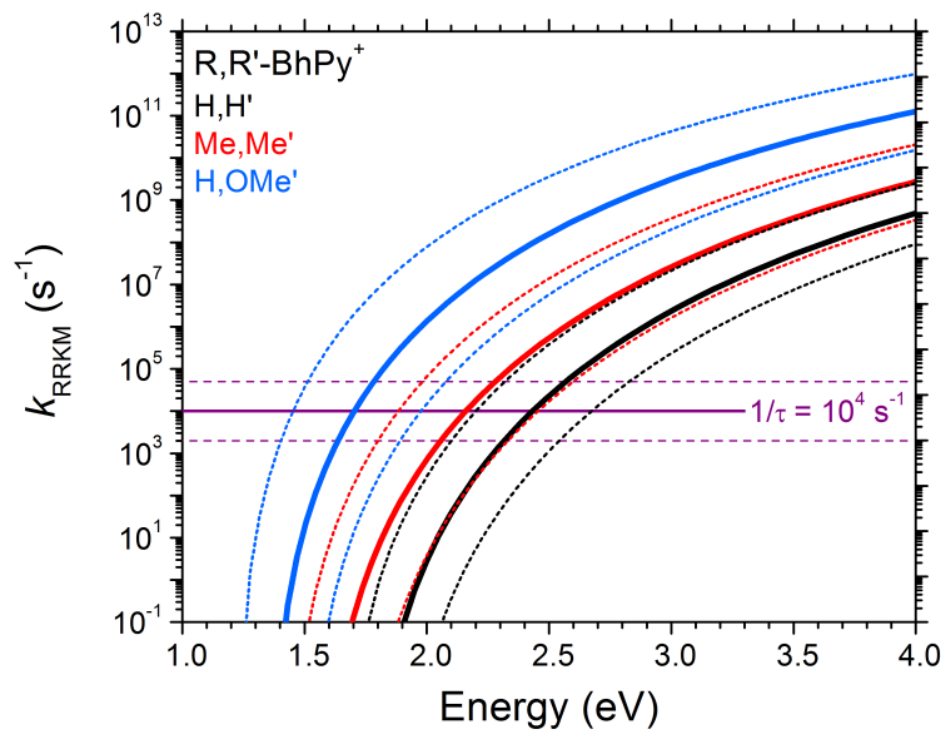

Figure S12. Microcanonical rate constants for the pyridine loss of benzhydrylpyridinium ions obtained from PSL/RRKM calculations employing $E_{0}$ values from TCID experiments, and vibrational frequencies (scaled by 0.989 ) and geometries from B3LYP/6-311+G(d,p) calculations. The intersections between the purple lines and the solid $k(E)$ curves correspond to the appearance energies of the dissociation reactions under the assumption of an experimental time scale of $T=10^{-4} \mathrm{~S}$ (solid purple line), $T=2 \cdot 10^{-5} \mathrm{~S}$ (upper dashed purple line) and $T=5 \cdot 10^{-4} \mathrm{~s}$ (lower dashed purple line). Dashed $k(E)$ curves represent the rate constants calculated for $E_{0} \pm \Delta E_{0}$ (with $\Delta E_{0}$ being the experimental uncertainty of the determined $E_{0}$ values). The intersections between the purple lines and the dashed $k(E)$ curves were used to derive error bars for the appearance energies resulting from the uncertainties in $E_{0}$. For the determined values, see Tables S2-S4. 
Table S2. Appearance energies $E_{\text {app }}$ for the pyridine loss of benzhydrylpyridinium and benzylpyridinium ions assuming an experimental time scale of $T=10^{-4} \mathrm{~s}$. The appearance energies were obtained on the basis of microcanonical rate constants, which were determined using $E_{0}$ values from quantum chemical calculations and TCID experiments (see Figures S11 and S12, respectively). The kinetic shift energy $E_{\mathrm{ks}}$ is the difference between $E_{\text {app }}$ and the underlying threshold energy $E_{0}$. All values are given in $\mathrm{eV}$.

\begin{tabular}{|c|c|c|c|c|}
\hline & $E_{\text {app }}$ from $E_{0}($ calc $)$ & $E_{\mathrm{ks}}$ from $E_{0}(\mathrm{calc})$ & $E_{\text {app }}$ from $E_{0}(T C I D)$ & $E_{\mathrm{ks}}$ from $E_{0}(\mathrm{TCID})$ \\
\hline $\mathrm{H}, \mathrm{H}^{\prime}-\mathrm{BhPy}^{+}$ & 2.31 & 0.57 & $2.43 \pm 0.24$ & $0.64 \pm 0.13$ \\
\hline $\mathrm{Me}, \mathrm{Me}^{\prime}-\mathrm{BhPy}^{+}$ & 2.05 & 0.53 & $2.16 \pm 0.29$ & $0.61 \pm 0.16$ \\
\hline $\mathrm{H}, \mathrm{OMe}^{\prime}-\mathrm{BhPy}^{+}$ & 1.76 & 0.35 & $1.70 \pm 0.27$ & $0.33 \pm 0.13$ \\
\hline $\mathrm{Me}, \mathrm{OMe}^{\prime}-\mathrm{BhPy}^{+}$ & 1.70 & 0.37 & & \\
\hline $\mathrm{OMe} \mathrm{OMe}^{\prime}-\mathrm{BhPy}^{+}$ & 1.47 & 0.29 & & \\
\hline $\mathrm{NPh}_{2}, \mathrm{NPh}_{2}{ }^{\prime}-\mathrm{BhPy}^{+}$ & 0.97 & 0.27 & & \\
\hline $\mathrm{NO}_{2}-\mathrm{BnPy}^{+}$ & 4.44 & 1.57 & $4.68 \pm 0.29^{a}$ & $1.64 \pm 0.17^{b}$ \\
\hline $\mathrm{CN}-\mathrm{BnPy}^{+}$ & 4.14 & 1.36 & & \\
\hline $\mathrm{H}-\mathrm{BnPy}^{+}$ & 3.46 & 0.95 & $3.46 \pm 0.30^{a}$ & $0.88 \pm 0.15^{b}$ \\
\hline $\mathrm{Cl}-\mathrm{BnPy}^{+}$ & 3.38 & 0.97 & & \\
\hline $\mathrm{Me}-\mathrm{BnPy}^{+}$ & 3.18 & 0.92 & $3.05 \pm 0.26^{a}$ & $0.79 \pm 0.13^{b}$ \\
\hline 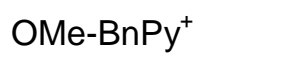 & 2.35 & 0.50 & $2.47 \pm 0.15^{a}$ & $0.54 \pm 0.07^{b}$ \\
\hline
\end{tabular}

${ }^{a}$ Values taken from ref. $5 .{ }^{b}$ Values derived from ref. 5. 
Table S3. Appearance energies $E_{\text {app }}$ for the pyridine loss of benzhydrylpyridinium and benzylpyridinium ions assuming an experimental time scale of $T=2 \cdot 10^{-5} \mathrm{~s}$. The appearance energies were obtained on the basis of microcanonical rate constants, which were determined using $E_{0}$ values from quantum chemical calculations and TCID experiments (see Figures S11 and S12, respectively). The kinetic shift energy $E_{\mathrm{ks}}$ is the difference between $E_{\text {app }}$ and the underlying threshold energy $E_{0}$. All values are given in $\mathrm{eV}$.

\begin{tabular}{|c|c|c|c|c|}
\hline & $E_{\text {app }}$ from $E_{0}($ calc $)$ & $E_{\mathrm{ks}}$ from $E_{0}($ calc $)$ & $E_{\text {app }}$ from $E_{0}(T C I D)$ & $E_{\mathrm{ks}}$ from $E_{0}(\mathrm{TCID})$ \\
\hline $\mathrm{H}, \mathrm{H}^{\prime}-\mathrm{BhPy}^{+}$ & 2.44 & 0.70 & $2.57 \pm 0.26$ & $0.78 \pm 0.15$ \\
\hline $\mathrm{Me}, \mathrm{Me}^{\prime}-\mathrm{BhPy}^{+}$ & 2.15 & 0.64 & $2.28 \pm 0.32$ & $0.73 \pm 0.19$ \\
\hline $\mathrm{H}, \mathrm{OMe}^{\prime}-\mathrm{BhPy}^{+}$ & 1.84 & 0.43 & $1.78 \pm 0.30$ & $0.41 \pm 0.16$ \\
\hline $\mathrm{Me}, \mathrm{OMe}^{\prime}-\mathrm{BhPy}^{+}$ & 1.78 & 0.45 & & \\
\hline OMe,OMe'-BhPy ${ }^{+}$ & 1.53 & 0.36 & & \\
\hline $\mathrm{NPh}_{2}, \mathrm{NPh}_{2}{ }^{\prime}-\mathrm{BhPy}^{+}$ & 1.02 & 0.32 & & \\
\hline $\mathrm{NO}_{2}-\mathrm{BnPy}^{+}$ & 4.69 & 1.82 & $4.95 \pm 0.33^{a}$ & $1.91 \pm 0.21^{a}$ \\
\hline $\mathrm{CN}_{-\mathrm{BnPy}^{+}}$ & 4.37 & 1.60 & & \\
\hline $\mathrm{H}-\mathrm{BnPy}^{+}$ & 3.66 & 1.14 & $3.63 \pm 0.32^{a}$ & $1.05 \pm 0.17^{a}$ \\
\hline $\mathrm{Cl}-\mathrm{BnPy}^{+}$ & 3.58 & 1.17 & & \\
\hline $\mathrm{Me}-\mathrm{BnPy}^{+}$ & 3.36 & 1.10 & $3.20 \pm 0.29^{a}$ & $0.94 \pm 0.16^{a}$ \\
\hline $\mathrm{OMe}^{-\mathrm{BnPy}^{+}}$ & 2.48 & 0.62 & $2.59 \pm 0.17^{a}$ & $0.66 \pm 0.09^{a}$ \\
\hline
\end{tabular}

${ }^{2}$ Values derived from Figure $\mathrm{S} 1$ of ref. 5. 
Table S4. Appearance energies $E_{\text {app }}$ for the pyridine loss of benzhydrylpyridinium and benzylpyridinium ions assuming an experimental time scale of $T=5 \cdot 10^{-4} \mathrm{~s}$. The appearance energies were obtained on the basis of microcanonical rate constants, which were determined using $E_{0}$ values from quantum chemical calculations and TCID experiments (see Figures S11 and S12, respectively). The kinetic shift energy $E_{\mathrm{ks}}$ is the difference between $E_{\text {app }}$ and the underlying threshold energy $E_{0}$. All values are given in $\mathrm{eV}$.

\begin{tabular}{|c|c|c|c|c|}
\hline & $E_{\text {app }}$ from $E_{0}($ calc $)$ & $E_{\mathrm{ks}}$ from $E_{0}(\mathrm{calc})$ & $E_{\text {app }}$ from $E_{0}(T C I D)$ & $E_{\mathrm{ks}}$ from $E_{0}(\mathrm{TCID})$ \\
\hline $\mathrm{H}, \mathrm{H}^{\prime}-\mathrm{BhPy}^{+}$ & 2.20 & 0.46 & $2.31 \pm 0.23$ & $0.52 \pm 0.12$ \\
\hline $\mathrm{Me}, \mathrm{Me}^{\prime}-\mathrm{BhPy}^{+}$ & 1.95 & 0.44 & $2.06 \pm 0.27$ & $0.51 \pm 0.14$ \\
\hline $\mathrm{H}, \mathrm{OMe}^{\prime}-\mathrm{BhPy}^{+}$ & 1.68 & 0.28 & $1.63 \pm 0.26$ & $0.26 \pm 0.12$ \\
\hline $\mathrm{Me}, \mathrm{OMe}^{\prime}-\mathrm{BhPy}^{+}$ & 1.62 & 0.30 & & \\
\hline OMe,OMe'-BhPy ${ }^{+}$ & 1.41 & 0.24 & & \\
\hline $\mathrm{NPh}_{2}, \mathrm{NPh}_{2}{ }^{\prime}-\mathrm{BhPy}^{+}$ & 0.93 & 0.23 & & \\
\hline $\mathrm{NO}_{2}-\mathrm{BnPy}^{+}$ & 4.22 & 1.35 & $4.44 \pm 0.28^{a}$ & $1.40 \pm 0.16^{a}$ \\
\hline $\mathrm{CN}_{-\mathrm{BnPy}^{+}}$ & 3.94 & 1.16 & & \\
\hline $\mathrm{H}-\mathrm{BnPy}^{+}$ & 3.29 & 0.78 & $3.30 \pm 0.28^{a}$ & $0.72 \pm 0.13^{a}$ \\
\hline $\mathrm{Cl}-\mathrm{BnPy}^{+}$ & 3.22 & 0.81 & & \\
\hline $\mathrm{Me}-\mathrm{BnPy}^{+}$ & 3.02 & 0.76 & $2.90 \pm 0.26^{a}$ & $0.64 \pm 0.13^{a}$ \\
\hline $\mathrm{OMe}^{-\mathrm{BnPy}^{+}}$ & 2.25 & 0.40 & $2.36 \pm 0.15^{a}$ & $0.43 \pm 0.07^{a}$ \\
\hline
\end{tabular}

${ }^{2}$ Values derived from Figure $\mathrm{S} 1$ of ref. 5. 


\section{8) Further Results from Survival Yield Measurements and Analysis}
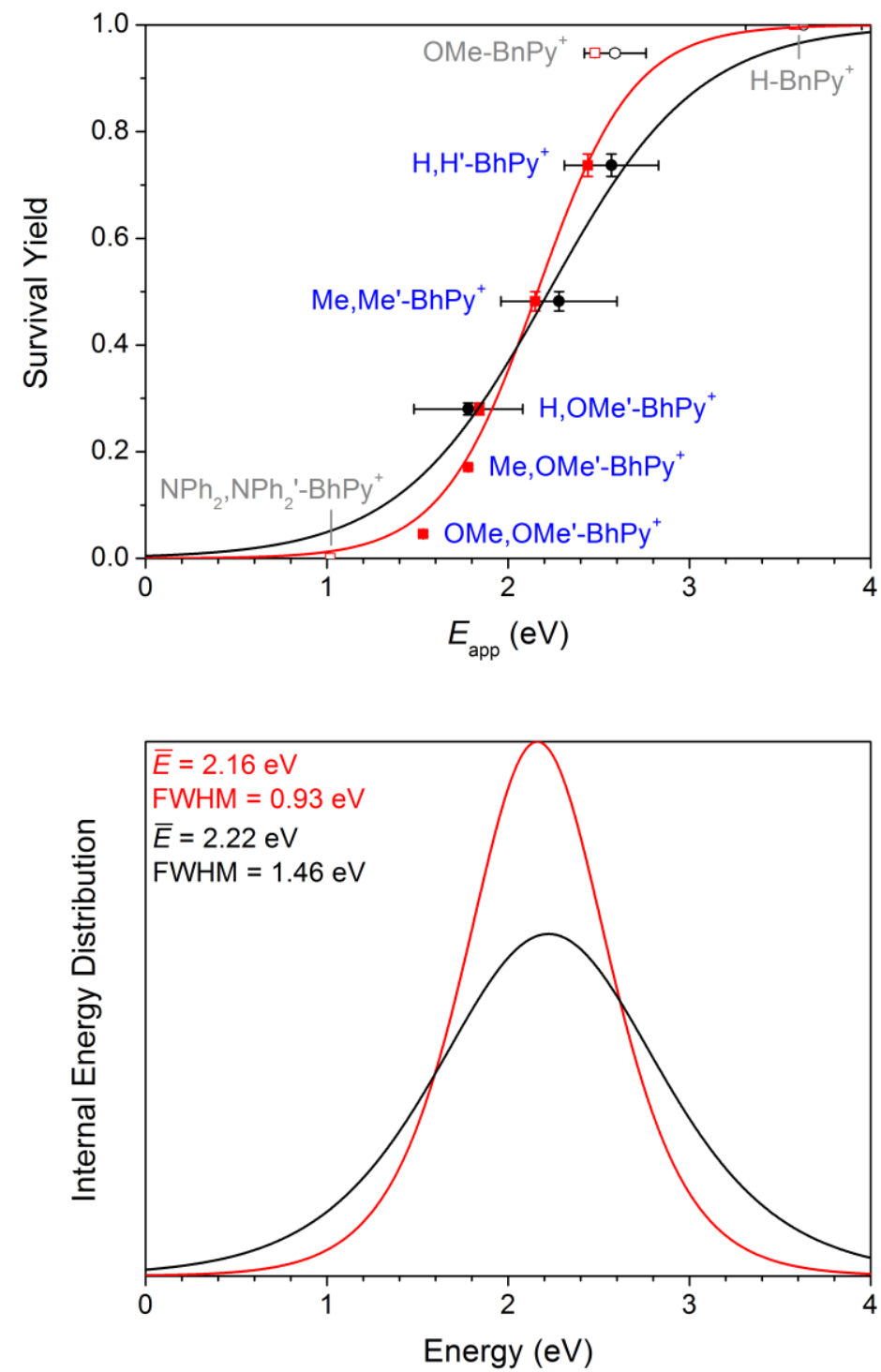

Figure S13. Top: Measured survival yields for the applied thermometer ions (sprayed from dichloromethane) plotted against appearance energies (for $T=2 \cdot 10^{-5} \mathrm{~s}$ ) obtained on the basis of calculated (red squares) and experimental $E_{0}$ values (black circles), and logistic regressions (red and black line; $R^{2}=0.98$ and 0.91 , respectively). For the regression analysis, only the data points represented by filled symbols were considered. Bottom: Derived internal energy distributions (red and black line). 

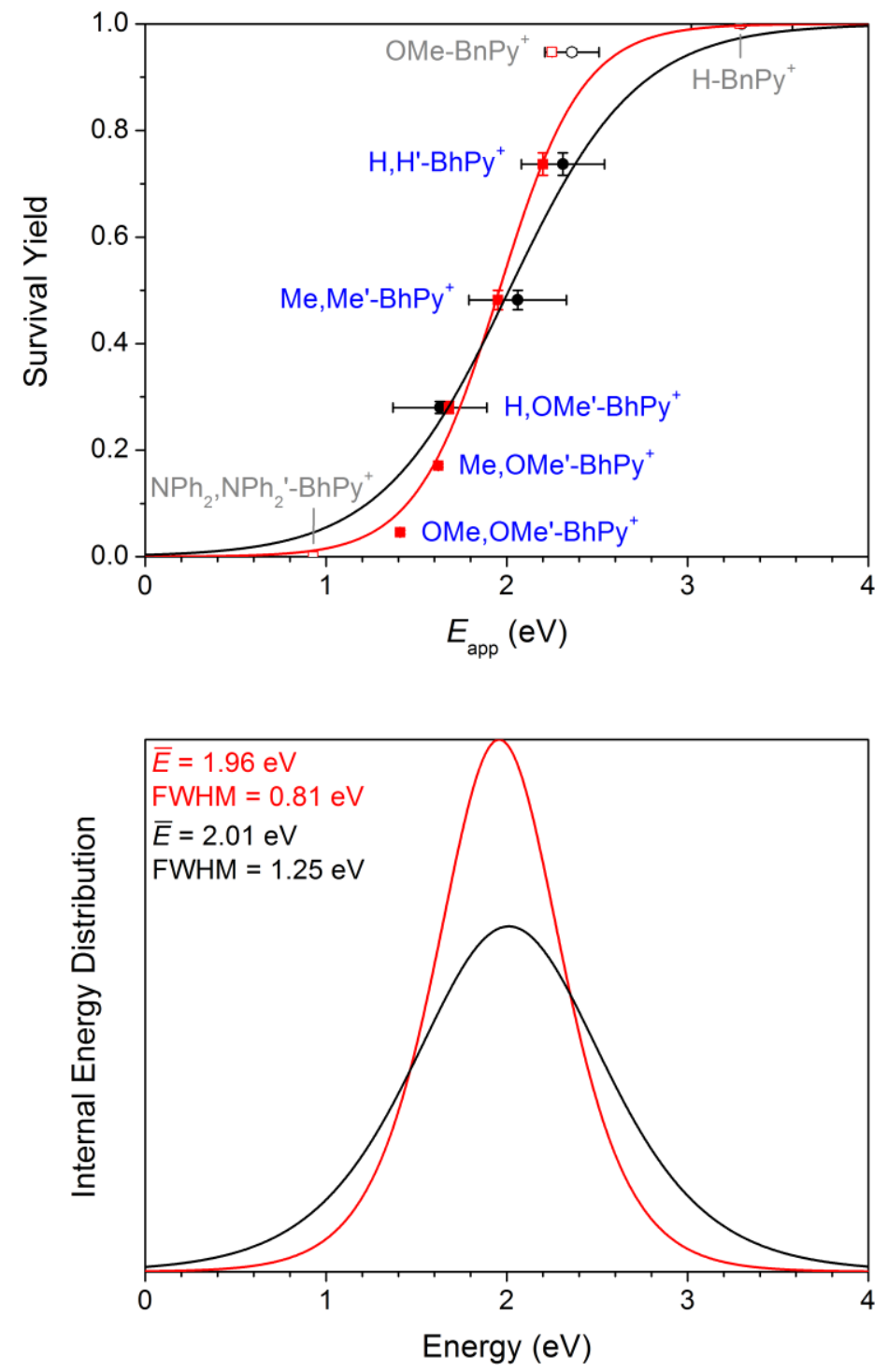

Figure S14. Top: Measured survival yields for the applied thermometer ions (sprayed from dichloromethane) plotted against appearance energies (for $T=5 \cdot 10^{-4} \mathrm{~s}$ ) obtained on the basis of calculated (red squares) and experimental $E_{0}$ values (black circles), and logistic regressions (red and black line; $R^{2}=0.98$ and 0.91 , respectively). For the regression analysis, only the data points represented by filled symbols were considered. Bottom: Derived internal energy distributions (red and black line). 

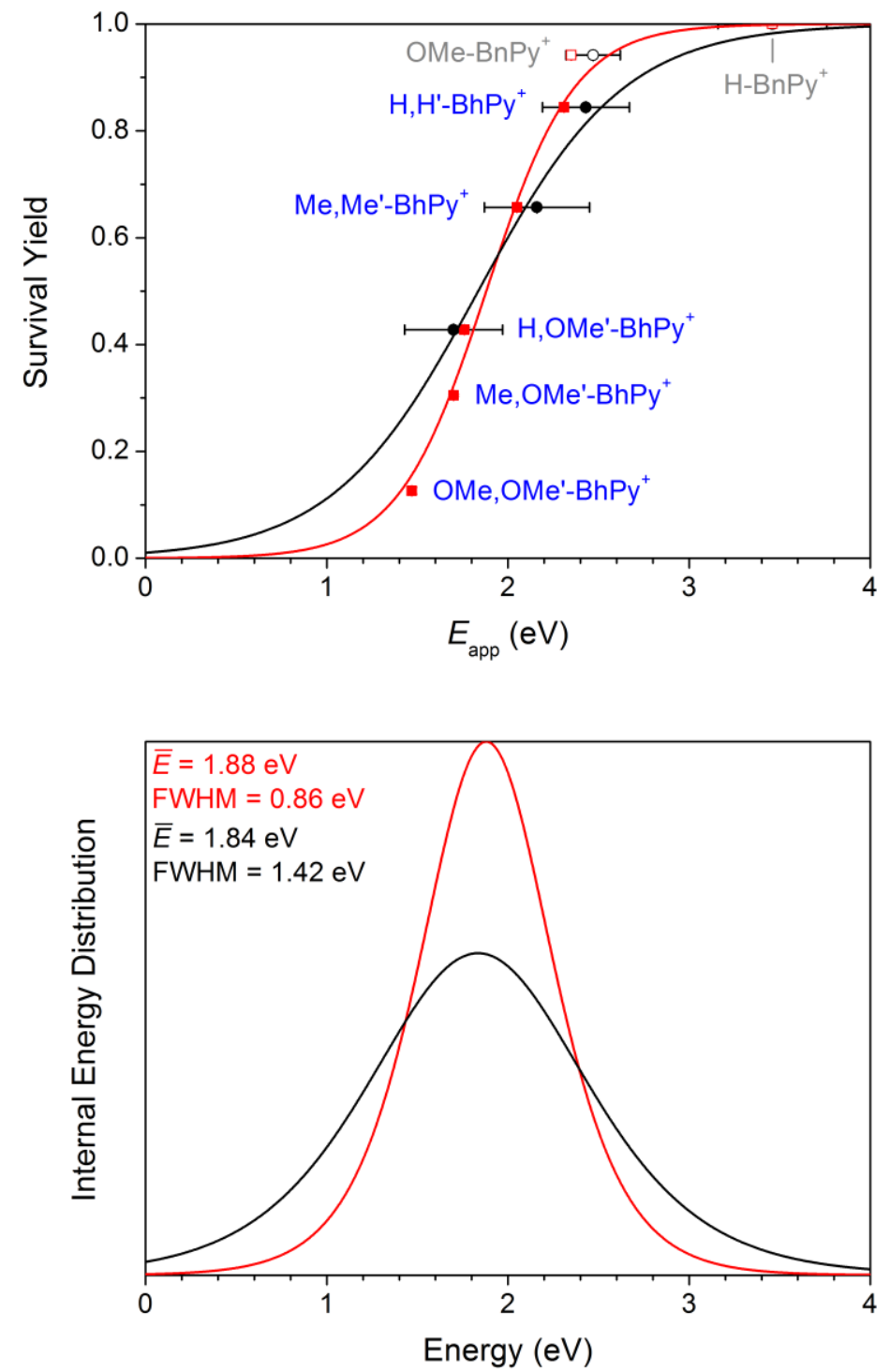

Figure S15. Top: Measured survival yields for the applied thermometer ions (sprayed from methanol) plotted against appearance energies (for $T=10^{-4} \mathrm{~s}$ ) obtained on the basis of calculated (red squares) and experimental $E_{0}$ values (black circles), and logistic regressions (red and black line; $R^{2}=0.98$ and 0.95 , respectively). For the regression analysis, only the data points represented by filled symbols were considered. Bottom: Derived internal energy distributions (red and black line). 

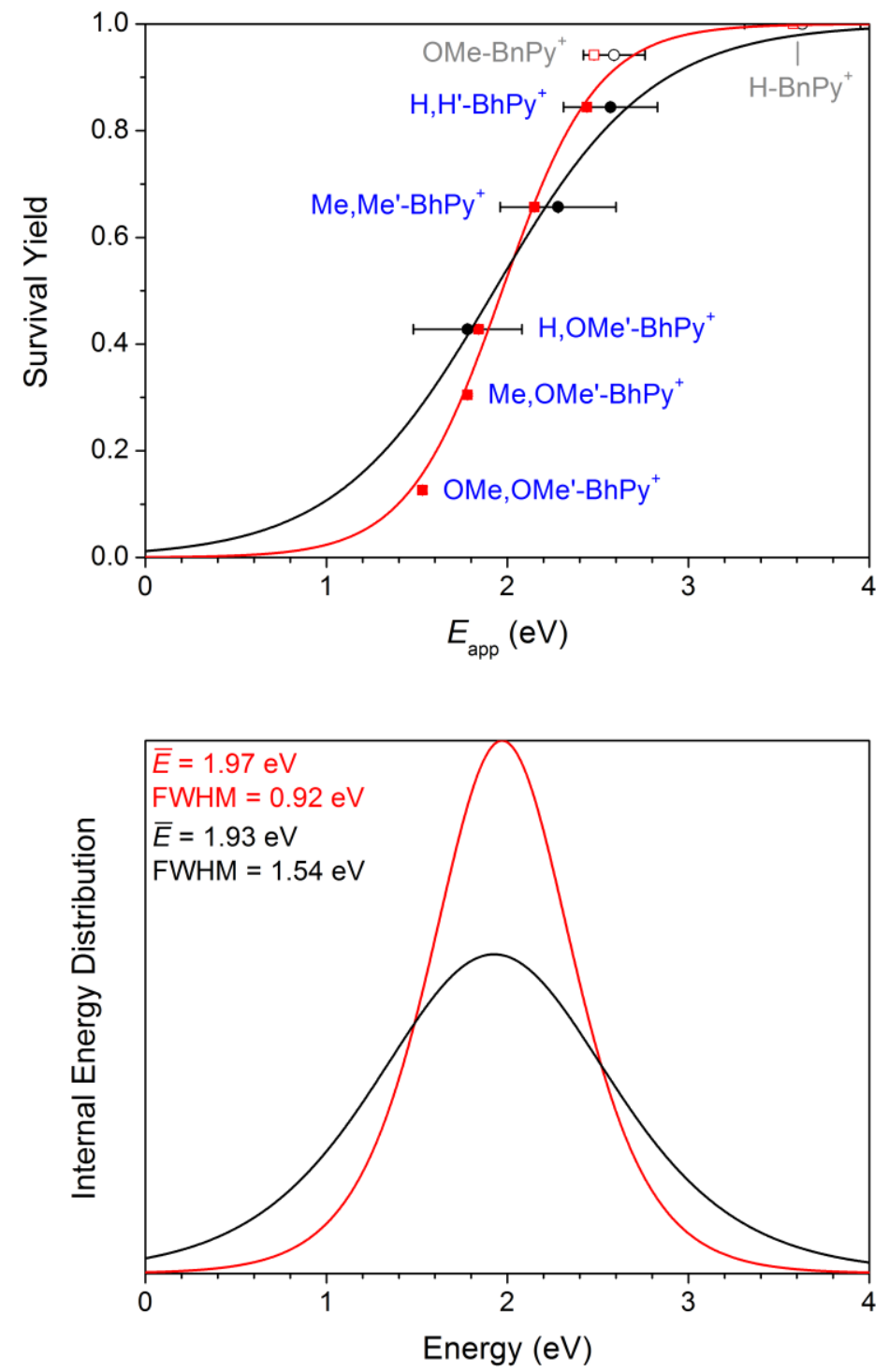

Figure S16. Top: Measured survival yields for the applied thermometer ions (sprayed from methanol) plotted against appearance energies (for $T=2 \cdot 10^{-5} \mathrm{~s}$ ) obtained on the basis of calculated (red squares) and experimental $E_{0}$ values (black circles), and logistic regressions (red and black line; $R^{2}=0.98$ and 0.95 , respectively). For the regression analysis, only the data points represented by filled symbols were considered. Bottom: Derived internal energy distributions (red and black line). 

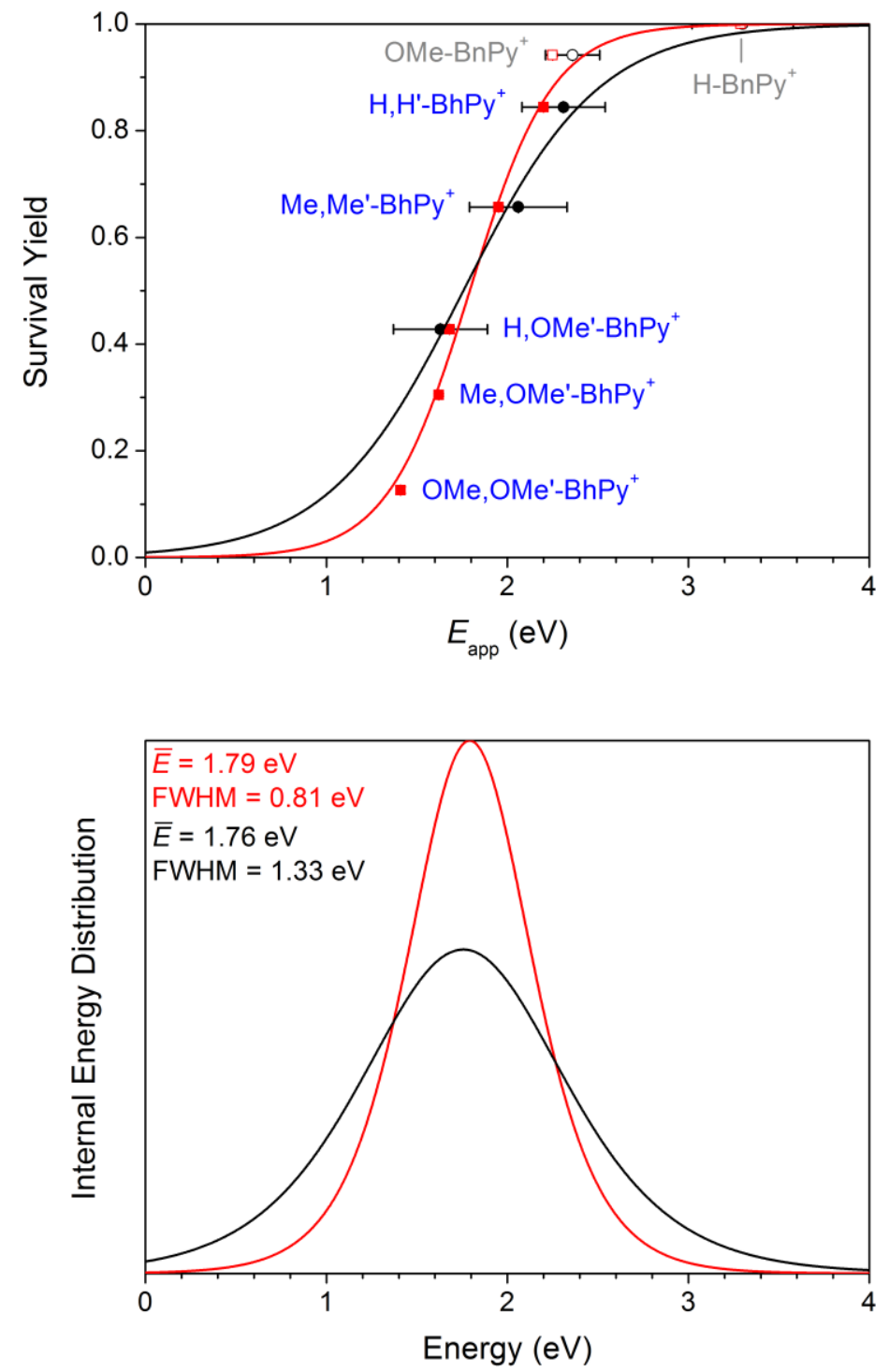

Figure S17. Top: Measured survival yields for the applied thermometer ions (sprayed from methanol) plotted against appearance energies (for $T=5 \cdot 10^{-4} \mathrm{~s}$ ) obtained on the basis of calculated (red squares) and experimental $E_{0}$ values (black circles), and logistic regressions (red and black line; $R^{2}=0.98$ and 0.95 , respectively). For the regression analysis, only the data points represented by filled symbols were considered. Bottom: Derived internal energy distributions (red and black line). 

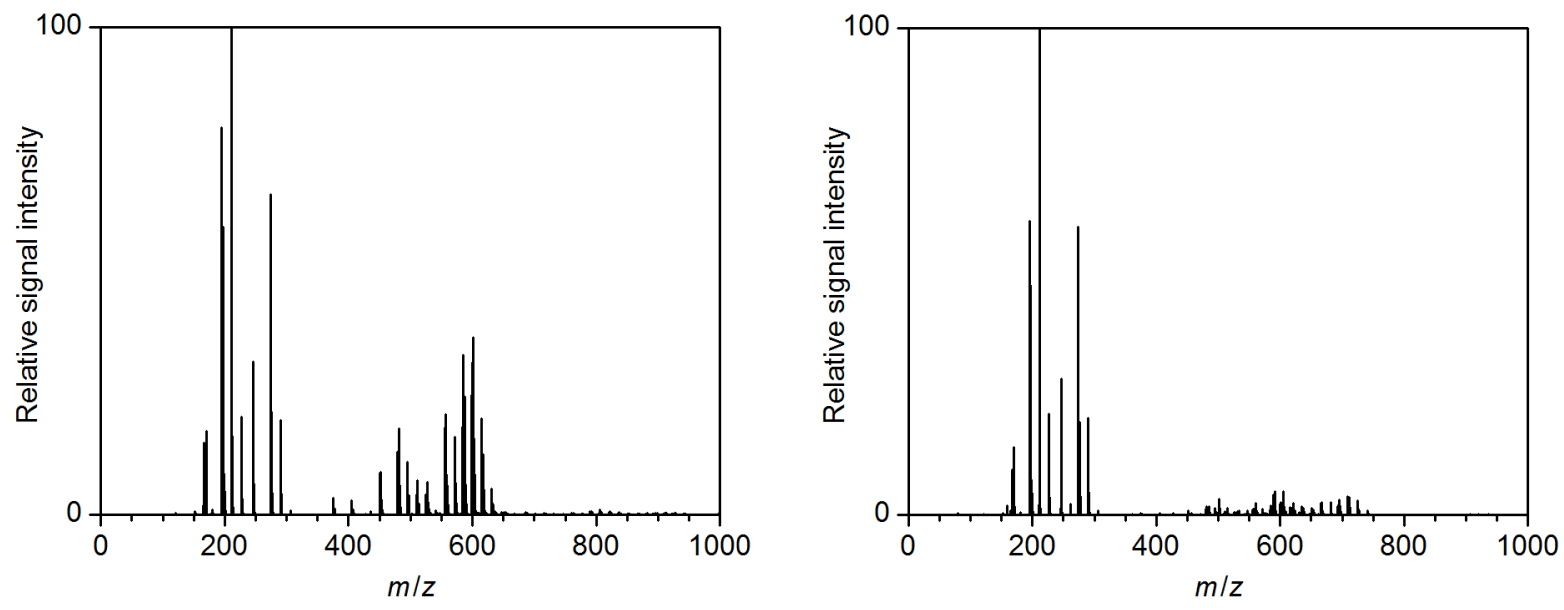

Figure S18. Left: Positive-ion mode ESI mass spectrum of a solution of six benzhydrylpyridinium and two benzylpyridinium salts (each $1 \mathrm{~mm}$ in dichloromethane). In the higher mass range $(\mathrm{m} / \mathrm{z}>400)$ the oligomeric adducts (R, $\left.\mathrm{R}^{\prime}-\mathrm{BhPy}\right)_{n} \mathrm{Cl}_{n-1}{ }^{+}(n=2,3)$ are visible. Right: Positive-ion mode ESI mass spectrum of a solution of six benzhydrylpyridinium and two benzylpyridinium salts (each $1 \mathrm{mM}$ in dichloromethane) with added $\mathrm{AgPF}_{6}(1$ equiv. relative to total concentration of $\mathrm{Cl}^{-}$). The addition of $\mathrm{AgPF}_{6}$ significantly reduces the signal intensities of oligomeric species. For the assignment of the thermometer ions signals, see Figure S19.
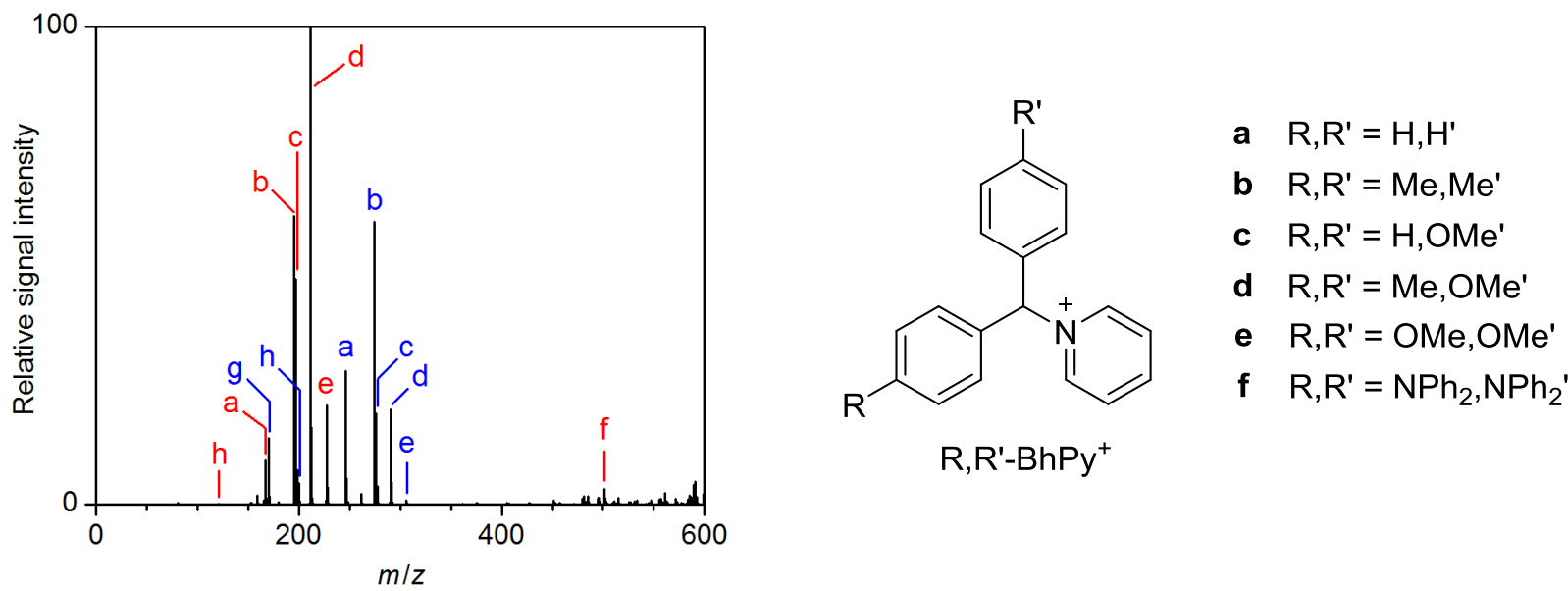

Figure S19. Positive-ion mode ESI mass spectra of a solution of six benzhydrylpyridinium and two benzylpyridinium salts (each $1 \mathrm{~mm}$ ) in dichloromethane (left). Labels referring to intact pyridinium species are given in blue, those of the corresponding benzhydrylium or benzylium fragments in red. $\mathrm{R}, \mathrm{R}^{\prime}-\mathrm{BhPy}^{+} / \mathrm{R}, \mathrm{R}^{\prime}-\mathrm{Bh}^{+}$

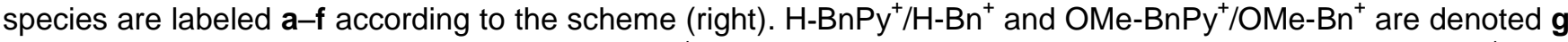
and $\mathbf{h}$, respectively. No intact $\mathrm{NPh}_{2}, \mathrm{NPh}_{2}{ }^{\prime}-\mathrm{BhPy}^{+}$was detected. In contrast, no fragmentation of $\mathrm{H}-\mathrm{BnPy}^{+}$was observed. Apart from the loss of pyridine, no other fragmentation channel was observed for the considered thermometer ions. 


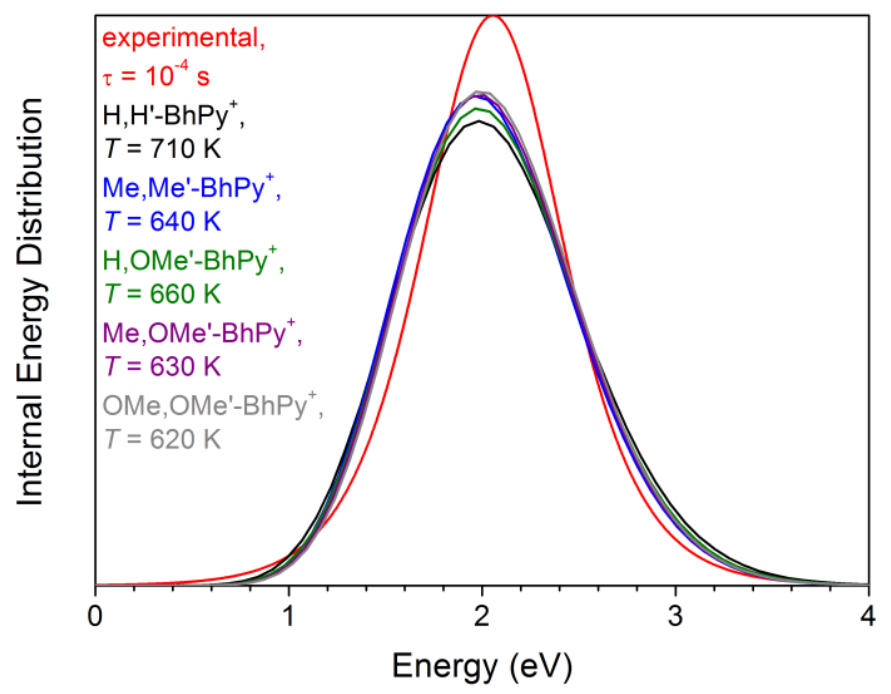

Figure S20. Maxwell-Boltzmann distributions of rovibrational states for $\mathrm{H}, \mathrm{H}^{\prime}-\mathrm{BhPy}^{+}$(black line), $\mathrm{Me}, \mathrm{Me}^{\prime}-\mathrm{BhPy}^{+}$ (blue line), $\mathrm{H}, \mathrm{OMe}^{-}-\mathrm{BhPy}^{+}$(green line), $\mathrm{Me}, \mathrm{OMe}^{-}-\mathrm{BhPy}^{+}$(purple line) and $\mathrm{OMe}, \mathrm{OMe}^{-}-\mathrm{BhPy}^{+}$ions (gray line) at temperatures that yield an average energy approximately equivalent to $2.06 \mathrm{eV}$. The latter is the mean energy of the experimentally determined internal energy distribution of these benzhydrylpyridinium ions sprayed from dichloromethane for $T=10^{-4} \mathrm{~s}$ (red line, cf. Figure 3). The Maxwell-Boltzmann distributions were calculated on the basis of geometries and vibrational frequencies from PBE0-D3BJ/def2-TZVP calculations.

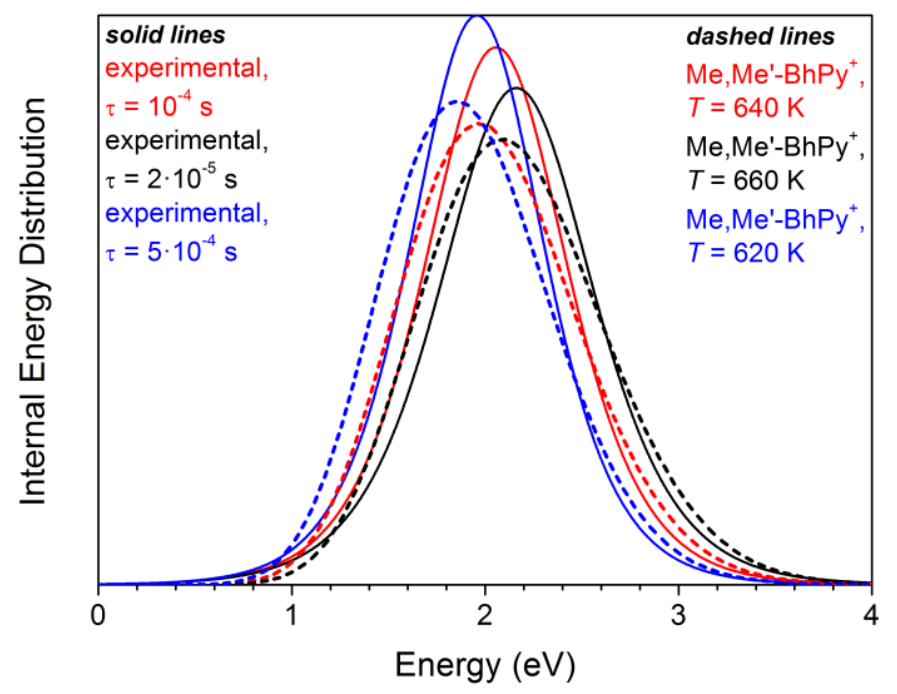

Figure S21. Maxwell-Boltzmann distributions of rovibrational states for $\mathrm{Me}, \mathrm{Me}^{\prime}-\mathrm{BhPy}^{+}$at temperatures that yield an average energy approximately equivalent to 2.06 (red dashed line), 2.16 (black dashed line) and $1.96 \mathrm{eV}$ (blue dashed line). The latter are the mean energies of the experimentally determined internal energy distributions of benzhydrylpyridinium ions sprayed from dichloromethane for $T=10^{-4} \mathrm{~S}$ (red solid line, cf. Figure 3 ), $T=2 \cdot 10^{-5} \mathrm{~S}$ (black solid line, cf. Figure S13) and $T=5 \cdot 10^{-4} \mathrm{~S}$ (blue solid line, cf. Figure S14), respectively. The MaxwellBoltzmann distributions were calculated on the basis of geometries and vibrational frequencies from PBE0D3BJ/def2-TZVP calculations. 


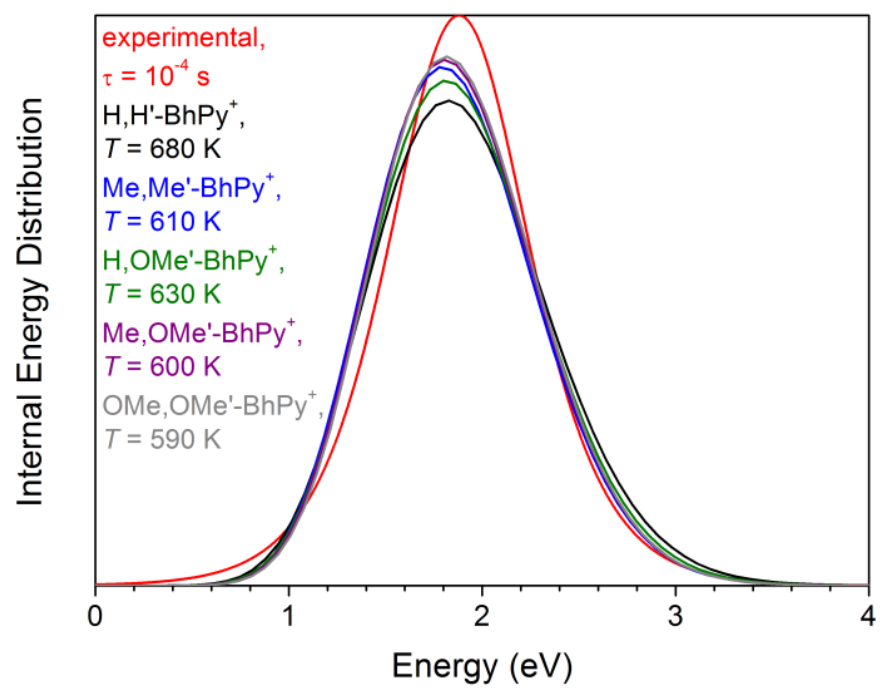

Figure S22. Maxwell-Boltzmann distributions of rovibrational states for $\mathrm{H}, \mathrm{H}^{\prime}-\mathrm{BhPy}^{+}$(black line), $\mathrm{Me}, \mathrm{Me}^{\prime}-\mathrm{BhPy}^{+}$

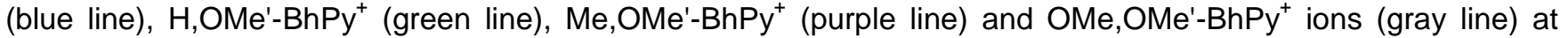
temperatures that yield an average energy approximately equivalent to $1.88 \mathrm{eV}$. The latter is the mean energy of the experimentally determined internal energy distribution of these benzhydrylpyridinium ions sprayed from methanol for $T=10^{-4} \mathrm{~S}$ (red line, cf. Figure S15). The Maxwell-Boltzmann distributions were calculated on the basis of geometries and vibrational frequencies from PBE0-D3BJ/def2-TZVP calculations.

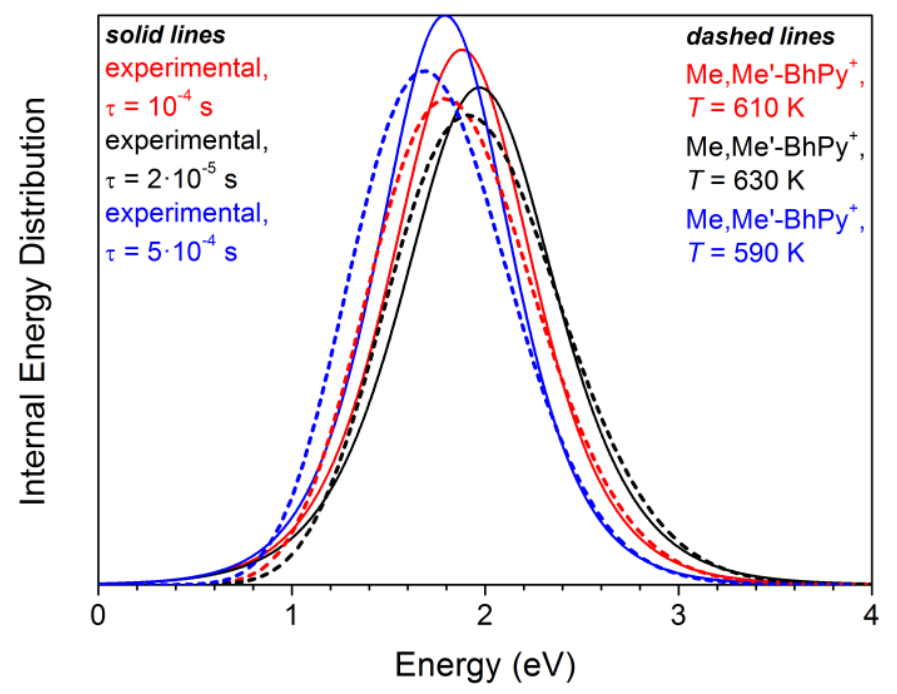

Figure S23. Maxwell-Boltzmann distributions of rovibrational states for $\mathrm{Me}, \mathrm{Me}^{\prime}-\mathrm{BhPy}^{+}$at temperatures that yield an average energy approximately equivalent to 1.88 (red dashed line), 1.97 (black dashed line) and $1.79 \mathrm{eV}$ (blue dashed line). The latter are the mean energies of the experimentally determined internal energy distributions of benzhydrylpyridinium ions sprayed from methanol for $T=10^{-4} \mathrm{~S}$ (red solid line, cf. Figure S15), $T=2 \cdot 10^{-5} \mathrm{~S}$ (black solid line, cf. Figure S16) and $T=5 \cdot 10^{-4} \mathrm{~S}$ (blue solid line, cf. Figure S17), respectively. The Maxwell-Boltzmann distributions were calculated on the basis of geometries and vibrational frequencies from PBE0-D3BJ/def2-TZVP calculations. 

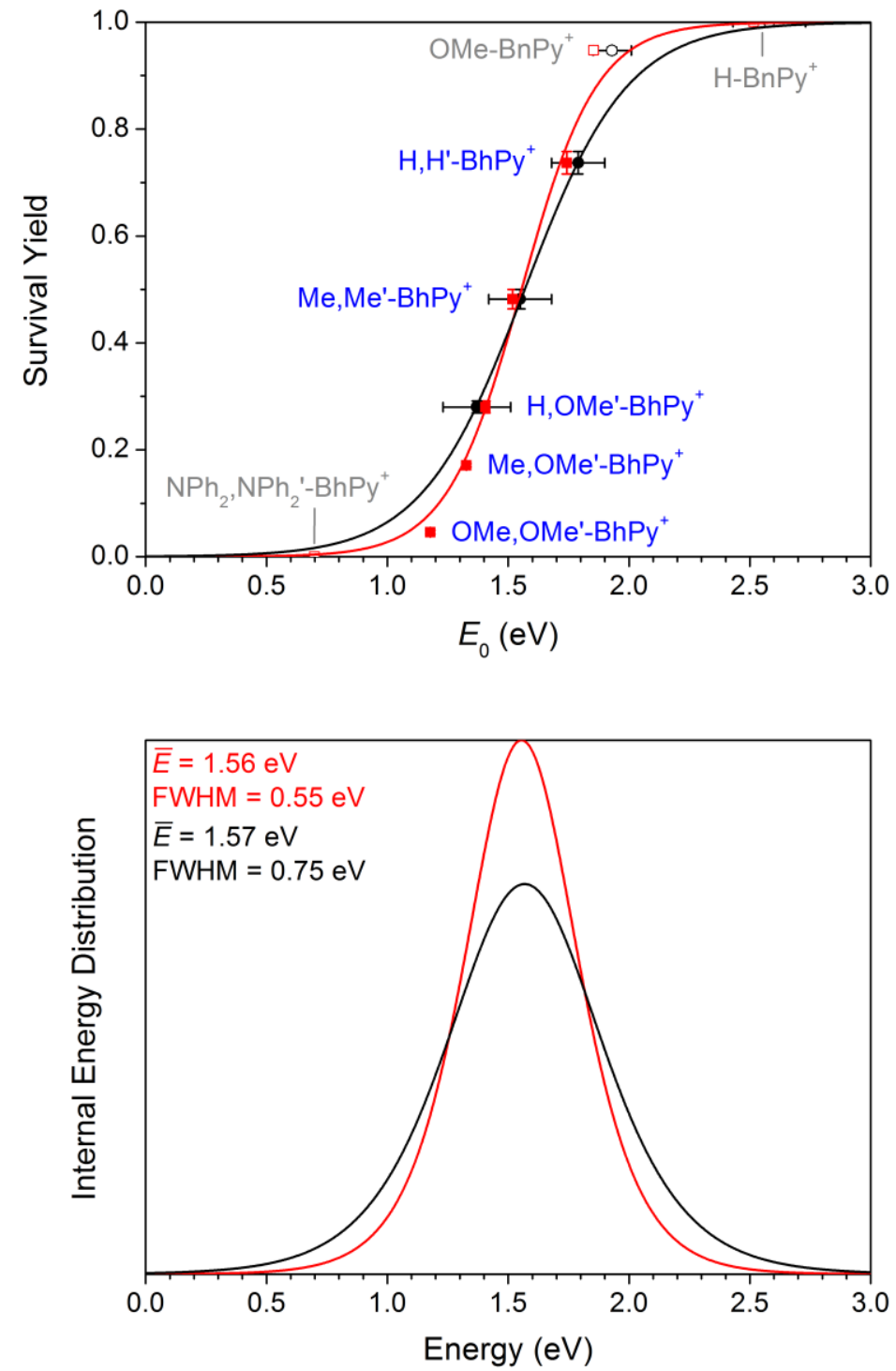

Figure S24. Top: Measured survival yields for the applied thermometer ions (sprayed from dichloromethane) plotted against calculated (red squares) and experimental threshold energies (black circles), and logistic regressions (red and black line; $R^{2}=0.98$ and 0.999 , respectively). For the regression analysis, only the data points represented by filled symbols were considered. Bottom: Derived internal energy distributions (red and black line). 

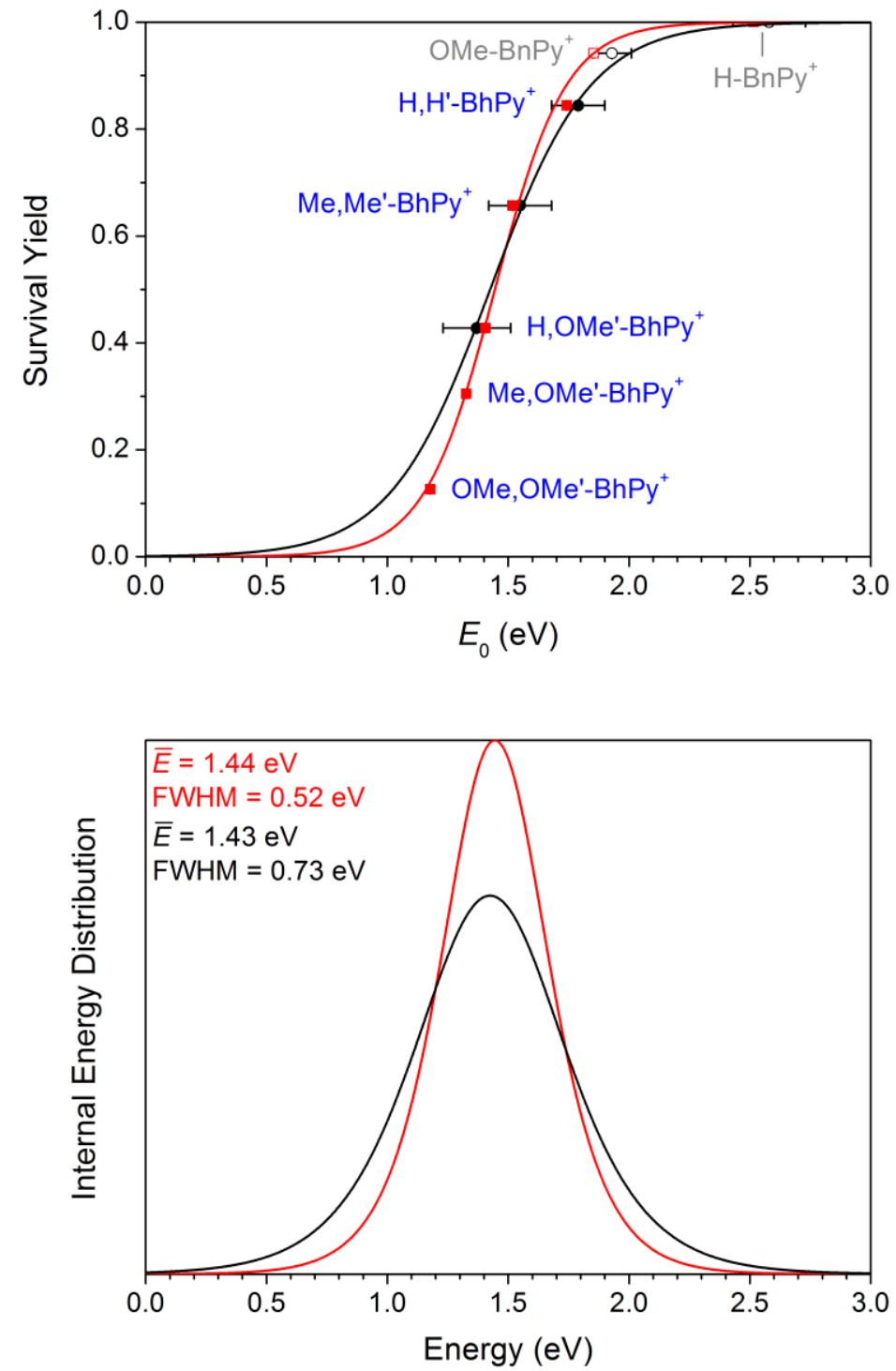

Figure S25. Top: Measured survival yields for the applied thermometer ions (sprayed from methanol) plotted against calculated (red squares) and experimental threshold energies (black circles), and logistic regressions (red and black line; $R^{2}=0.99$ and 0.99 , respectively). For the regression analysis, only the data points represented by filled symbols were considered. Bottom: Derived internal energy distributions (red and black line). 


\section{9) References}

(1) Neese, F.; Valeev, E. F. J. Chem. Theory Comput. 2011, 7, 33-43.

(2) Mayr, H.; Bug, T.; Gotta, M. F.; Hering, N.; Irrgang, B.; Janker, B.; Kempf, B.; Loos, R.; Ofial, A. R.; Remennikov, G.; Schimmel, H. J. Am. Chem. Soc. 2001, 123, 9500-9512.

(3) Brotzel, F.; Kempf, B.; Singer, T.; Zipse, H.; Mayr, H. Chem. Eur. J. 2007, 13, 336-345.

(4) Morsa, D.; Gabelica, V.; Rosu, F.; Oomens, J.; De Pauw, E. J. Phys. Chem. Lett. 2014, 5, 3787-3791.

(5) Carpenter, J. E.; McNary, C. P.; Furin, A.; Sweeney, A. F.; Armentrout, P. B. J. Am. Soc. Mass Spectrom. 2017, 28, 1876-1888. 


\section{0) Author Contributions}

R.R.: Synthesis and acquisition of analytical data of thermometer ions: lead

TCID measurements and data analysis: equal

Survival yield measurements and data analysis: lead

Writing of original draft: supporting

T.A.: Quantum chemical calculations and data analysis: lead

Acquisition of analytical data of thermometer ions: supporting

Kinetic shift calculations and data analysis: lead

Survival yield measurements and data analysis: supporting

Writing of original draft: equal

M.D.: TCID measurements and data analysis: equal

Kinetic shift calculations and data analysis: supporting

Writing of original draft: equal

P.B.A.: TCID measurements and data analysis: supporting

Kinetic shift calculations and data analysis: supporting

Writing of original draft: equal

Design of study: equal

K.K.: Survival yield measurements and data analysis: supporting

Writing of original draft: equal

Design of study: equal

All authors contributed to the final manuscript. 